\title{
Focem e Assimetrias infraestruturais no Mercosul: As Principais Características Apresentadas nos Últimos Anos
}

\author{
Focem and Asymmetries infrastructural in Mercosur: The Key Features Presented in \\ the Last Years \\ Michelle Lins de Moraes ${ }^{1}$ \\ Thauan Santos ${ }^{2}$
}

Resumo: As infraestruturas exercem um importante papel dentro das dinâmicas socioeconômicas, por influenciarem o grau de bem-estar social e de produtividade dos territórios. Em relação à atual situação do Mercado Comum do Sul (MERCOSUL), os problemas infraestruturais não se resumem ao seu atraso em relação aos países centrais, mas também contemplam as significativas discrepâncias existentes ao interno do bloco. Ao considerar a amplitude da temática, o principal objetivo deste trabalho é delinear algumas das principais características concernentes às assimetrias infraestruturais existentes no MERCOSUL (em termos de transporte, de telecomunicações e de energia); bem como ao papel do Fundo para a Convergência Estrutural do MERCOSUL (FOCEM) neste contexto.

Palavras-chave: Infraestrutura, FOCEM, MERCOSUL, Políticas Públicas.

Abstract: Infrastructures play an important role in the socio-economic dynamics, by influencing the degree of social well-being and productivity of territories. Regarding the current situation of the Southern Common Market (MERCOSUR), the infrastructural problems are not confined to its lags behind the developed countries, but also include significant existing internal block discrepancies. When considering the breadth of the subject, the main objective of this work is to outline some key features pertaining to existing internal MERCOSUR asymmetries infrastructure (in terms of transportation, telecommunications and energy); and the role of Fund for the Structural Convergence of MERCOSUR (FOCEM) in this realm.

Key-words: Infrastructure, FOCEM, MERCOSUR, Public Policy.

JEL: O21

\section{INTRODUÇÃO}

Apesar da escassez de dados socioeconômicos a nível subnacional, é notória a presença de um elevado nível de assimetria entre as regiões que compõem os países do MERCOSUL ${ }^{3}$, como ocorre na maior parte dos países subdesenvolvidos. Em termos de distribuição populacional, por exemplo, verifica-se que a média de concentração na principal área de cada país é de cerca $25 \%$. Segundo os dados elaborados pelos institutos nacionais de estatística, os dois países onde tal discrepância é mais acentuada são

\footnotetext{
1 Doutora em Economia pela Università degli Studi di Ferrara (Itália) e em Políticas Públicas pela Universidade Federal do Maranhão (Brasil). Professora da Universidad Católica del Norte (Chile). moraesbrasil@hotmail.com

2 Doutorando em Planejamento Energético pela COPPE/UFRJ e pesquisador do Centro de Estudos em Logística, Infraestrutura e Gestão (CELIG/COPPEAD/UFRJ). Professor da Universidade do Estado do Rio de Janeiro (Brasil)
}

Revista de Estudos Sociais | Ano 2014, N. 32, V. 16, Pag. 
Argentina, onde $46 \%$ da população está localizada na região de Buenos Aires (Grande Buenos Aires + Interior de Buenos Aires + Cidade Autônoma de Buenos Aires) e Uruguai, este último apresentando uma concentração demográfica de quase $40 \%$ na região de Montevideo.

No âmbito econômico, a discrepância pode ser confirmada através dos dados referentes à participação das áreas ao Produto Interno Bruto (PIB) nacional. No caso argentino, em 2009, a participação da cidade e da província de Buenos Aires era de cerca $60 \%$ (ver Gráfico 1). Por conta da indisponibilidade de uma série de dados temporais sobre a distribuição do PIB da Argentina por província ao longo dos anos, resta considerar que o nível de concentração atual é muito acentuado e que, segundo Acebeb (2008), as alterações relacionadas à redistribuição territorial do PIB nos últimos anos foram marginais. No caso do Brasil, a participação de São Paulo na produção do país era de $33 \%$ em 2010.

\section{Gráfico 1 - Distribuição do PIB por região}

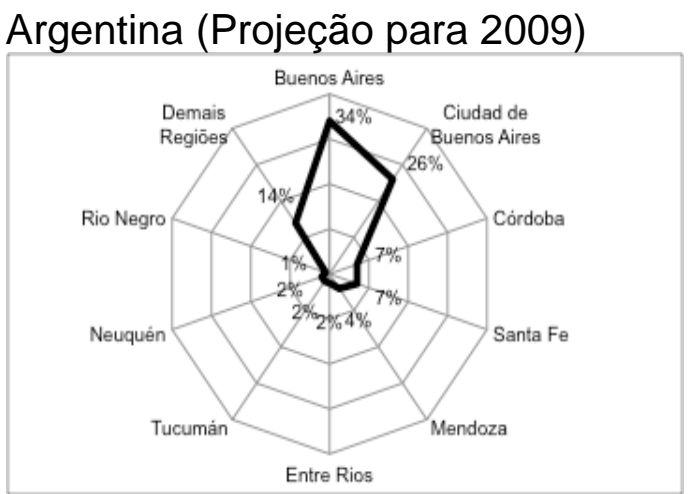

Fonte: ACEBEB (2008)

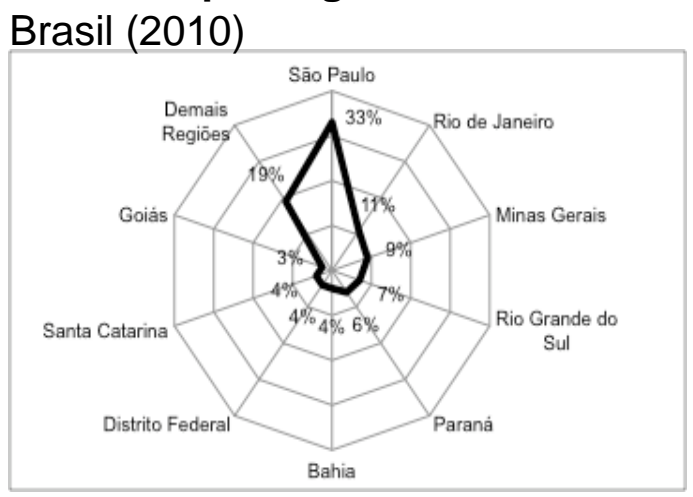

Fonte: IPEA

Uruguai (2005)

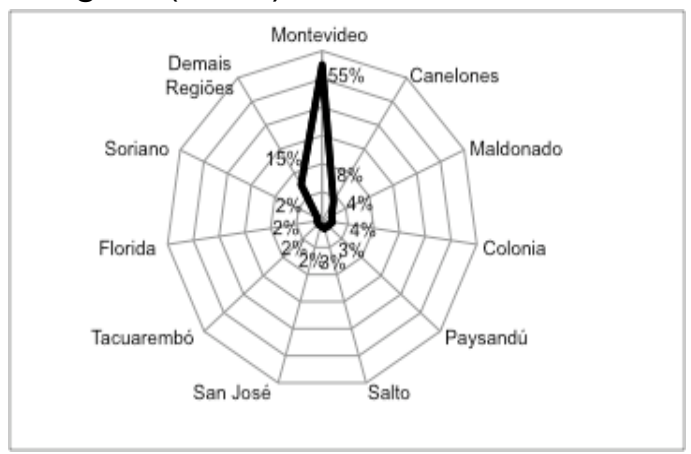

Fonte: El pais (2006)

Em relação ao Uruguai, em 2005, Montevidéu apresentava uma participação no PIB de $55 \%$. Os dados do Paraguai e da Venezuela servirão como fonte de análise para os nossos próximos trabalhos, dada a sua atual indisponibilidade.

O debate sobre o grau de importância da infraestrutura para 0 desenvolvimento de um território não é recente, nem consensual. Apesar disso, a hipótese que existe uma relação positiva entre os investimentos em tal área e o crescimento econômico é aceitável por grande parte dos estudiosos. Isso se 
deve ao fato que seja pouco contestável a hipótese que uma rede de transportes mais eficiente, por exemplo, possa melhorar os níveis de produtividade, além de aumentar o acesso a mercados e mão-de-obra (ALONSO \& SÁNCHEZ, 2012).

Considerando esta proposição, na próxima seção são analisados alguns aspectos relacionados à (in)disponibilidade de infraestrutura no MERCOSUL. Vale destacar que o presente paper tem como principal objetivo apresentar um retrato da atual infraestrutura dos países do MERCOSUL no que se refere à questão dos transportes, energia e telecomunicações. Sendo assim, estão ausentes análises aprofundadas acerca do modelo de desenvolvimento de cada um desses países, em detrimento do maior detalhamento dos dados apresentados. Apesar de, em determinados momentos, fazermos comparações desses dados com os mesmos para os países desenvolvidos, isso objetiva apenas permitir uma base de comparação. De fato, não se pretende desconsiderar o percurso histórico de desenvolvimento socioeconômico dos diferentes países nos distintos continentes, nem tampouco o papel do Estado, nesse processo.

\section{TRANSPORTES}

\subsection{Transporte Rodoviário}

Na matriz de transportes do MERCOSUL, a categoria rodoviária exerce um papel preponderante (SANTIAGO, 2011). Apesar disso, a quantidade e a qualidade das rodovias na referida localidade estão muito aquém daquelas encontradas em áreas mais desenvolvidas, como a Europa, por exemplo.

\section{Gráfico 2 - Provisão Rodoviária em Km por Km² de território em 2004}

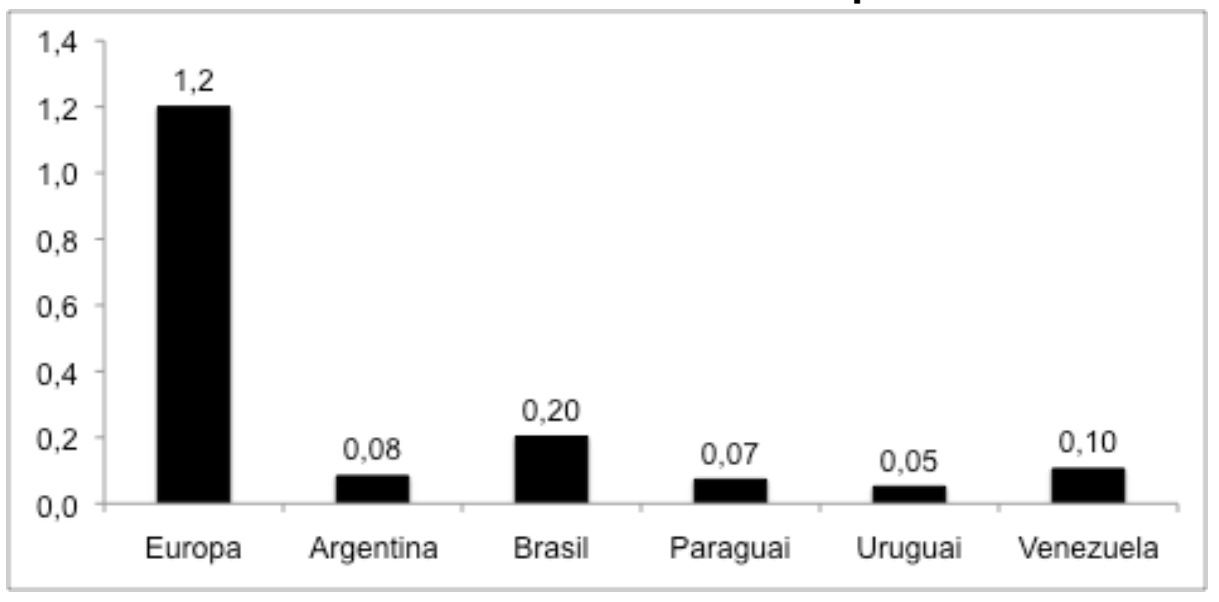

Fonte: Cepalstat

Em relação à quantidade de rodovias por $\mathrm{Km}^{2}$ de território, é possível observar que, em 2004, enquanto a cobertura rodoviária europeia era superior Revista de Estudos Sociais I Ano 2014, N. 32, V. 16, Pag. 
à $1 \mathrm{Km}$, no Brasil, país com o melhor desempenho entre os cinco membros do bloco sul-americano, tal número era de apenas 200 metros (ver Gráfico 2). A presença de profundas assimetrias no MERCOSUL pode ser verificada ao se constatar que a prestação brasileira era quatro vezes superior àquela uruguaia.

Sobre a qualidade das rodovias, segundo um ranking de 144 países elaborado pelo World Economic Fórum (WEF, 2014), Argentina, Brasil, Paraguai, Uruguai e Venezuela estariam, respectivamente, nas posições $103^{a}$, $120^{\mathrm{a}}, 132^{\mathrm{a}}$, $88^{\mathrm{a}}$ e $128^{\mathrm{a}}$, no período 2013-2014. Indicando não apenas o atraso das referidas nações em relação aos outros países, mas também a existência de assimetrias significativas entre os componentes do próprio bloco.

Os poucos dados a nível subnacional disponíveis sobre a distribuição da rede rodoviária nos países do MERCOSUL apontam a existência de disparidades expressivas entre as mencionadas regiões. No caso brasileiro (ver Tabela 1), é importante observar alguns aspectos inerentes a tais assimetrias. O primeiro deles é a presença de grandes extensões florestais, já que grande parte das regiões abaixo da média nacional é composta por uma fração da floresta amazônica. O segundo aspecto não faz parte da composição geográfica natural, mas da composição geográfica criada pelo homem, ou seja, as grandes porções de terra destinadas à agricultura.

Todavia, os fatores mencionados não são capazes de justificar os baixos níveis quantitativos e qualitativos do serviço prestado em todo o país. Neste cenário, apenas o Estado de Santa Catarina apresentaria um número de provisão compatível com aquele europeu, mas nada indica que em termos qualitativos tal compatibilidade perduraria.

Tabela 1 - Provisão Rodoviária por Estado Brasileiro em $\mathrm{Km}$ por $\mathrm{Km}^{2} \mathrm{em}$ 2008

\begin{tabular}{|l|l|l|l|l|l|}
\hline Região & Provisão & Região & Provisão & Região & Provisão \\
\hline Amazonas & 0,010 & Maranhão & 0,177 & Rio G. do Norte & 0,534 \\
\hline Pará & 0,031 & Piauí & 0,250 & Alagoas & 0,544 \\
\hline Roraima & 0,036 & Bahia & 0,256 & Rio G. do Sul & 0,566 \\
\hline Amapá & 0,051 & Sergipe & 0,264 & Rio de Janeiro & 0,597 \\
\hline Acre & 0,061 & Goiás & 0,288 & Paraná & 0,610 \\
\hline Mato Grosso & 0,072 & Distrito Federal & 0,305 & Paraíba & 0,632 \\
\hline Rondônia & 0,114 & Ceará & 0,364 & Espírito Santo & 0,747 \\
\hline Mato G. Sul & 0,120 & Pernambuco & 0,459 & São Paulo & 0,823 \\
\hline Tocantins & 0,133 & Minas Gerais & 0,479 & Santa Catarina & 1,138 \\
\hline Brasil $\mathbf{0 , 2 0 0}$ & & & & \\
\hline
\end{tabular}

Fonte: DNIT 
Tabela 2 - Provisão Rodoviária por Departamento Uruguaio em Km por $\mathrm{Km}^{2}$ em 2010

\begin{tabular}{|l|l|l|l|l|l|}
\hline Região & Provisão & Região & Provisão & Região & Provisão \\
\hline Salto & 0,023 & Durazno & 0,037 & Maldonado & 0,075 \\
\hline Treinta y Tres & 0,028 & Río Negro & 0,043 & San José & 0,087 \\
\hline Lavalleja & 0,029 & Rivera & 0,047 & Colonia & 0,093 \\
\hline Paysandú & 0,031 & Flores & 0,054 & Montevideo & 0,211 \\
\hline Artigas & 0,033 & Soriano & 0,058 & Canelones & 0,248 \\
\hline Cerro Largo & 0,036 & Florida & 0,059 & Uruguai & $\mathbf{0}, 050$ \\
\hline Tacuarembó & 0,036 & Rocha & 0,065 & & \\
\hline
\end{tabular}

Fonte: DNT

O nível de concentração das provisões rodoviárias também é elevado no Uruguai (ver Tabela 2), contudo, a diferença entre as regiões de pior e melhor desempenho é inferior àquela brasileira.

\subsection{Transporte Ferroviário}

A implantação de ferrovias nos países do bloco surgiu predominantemente da necessidade de interligar os centros produtores às regiões portuárias, característica esta, ainda hoje sobressalente na configuração da prestação de tal serviço. A forma com a qual a expansão desta modalidade de transportes ocorreu, geralmente através da instalação de ferrovias esparsas e não interligadas, fez com que a tipologia de equipamentos utilizados diferisse entre si e, consequentemente, constituísse um obstáculo não facilmente transcurável à integração regional. Os mencionados aspectos foram determinantes na reconfiguração da matriz de transporte local, ou seja, para a ampliação das redes rodoviárias e para a estagnação daquelas ferroviárias (NATAL, 1991).

"Entre Argentina e Brasil, a mudança de bitola impede que os trens atravessem a fronteira. O mesmo acontece entre Brasil e Uruguai. A guerra entre Argentina e Brasil, no distante ano de 1825, pelo controle da região que é hoje o Uruguai, e a Guerra do Paraguai, na segunda metade da década de 1860, deixaram uma cicatriz aberta na infraestrutura logística do Cone Sul. As ferrovias construídas no palco desses conflitos adotaram uma bitola diferente tanto das demais redes ferroviárias argentinas quanto das redes brasileiras. Garantia-se dessa maneira que os exércitos desses países não poderiam utilizar os trilhos para invadir um ao outro. Quase duzentos anos depois, as ferrovias são irrelevantes para as guerras, mas fundamentais para o comércio e a prosperidade dos povos desses países" (LACERDA, 2009).

Uma comparação entre a densidade de ferrovias na Europa e aquela presente nos dos cinco países do bloco confirma a existência de assimetrias tanto a nível inter como intra-regional (ver Gráfico 3). Enquanto na Europa a provisão é de cerca $40 \mathrm{Km}$ a cada mil $\mathrm{Km}^{2}$ de território, na Angentina, país com o melhor resultado entre os componentes do MERCOSUL, tal provisão é de somente $10,5 \mathrm{Km}$. Além disso, devemos ressaltar que a discrepância entre os países sul-americanos considerados não é menos relevante, visto que no

Revista de Estudos Sociais | Ano 2014, N. 32, V. 16, Pag. 
Paraguai e na Venezuela as referidas provisões eram, respectivamente, de apenas 0,09 e 0,8 Km.

\section{Gráfico 3 - Provisão Rede Ferroviária em $\mathrm{Km}$ por mil $\mathrm{Km}^{2}$ de território em 2007}

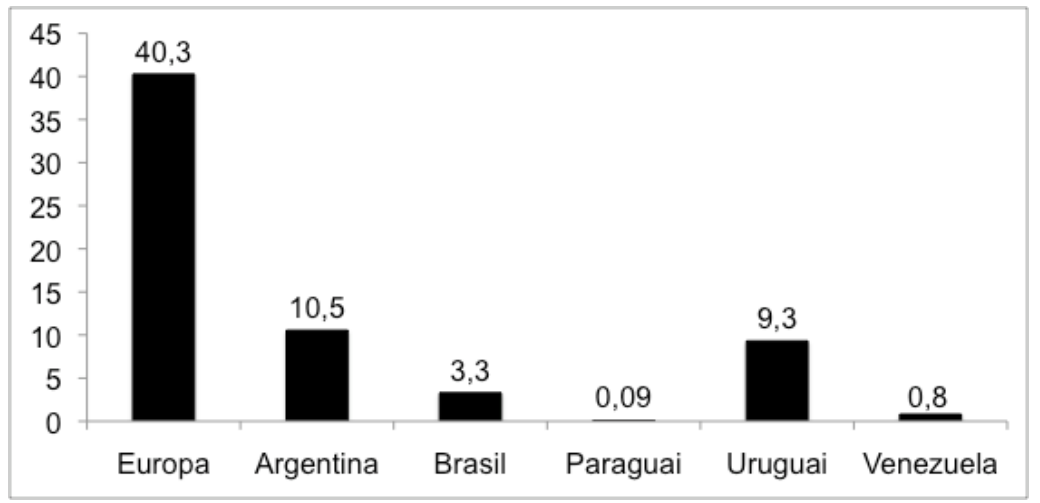

Fonte: Cepalstat

Embora os dados a nível subnacional sobre a distribuição geográfica do setor ferroviário venezuelano não estejam disponíveis, os mapas do Instituto de Ferrocarriles del Estado (IFE) indicam as localidades nas quais a prestação de tais serviços se faz presente. O mapa localizado à esquerda da Figura 1 evidencia o trecho atualmente em atividade, enquanto aquele à direita exibe as linhas inoperantes nas quais foram iniciadas obras de recuperação. Este último trecho possui cerca de $174 \mathrm{Km}$ e, segundo o IFE, permaneceu inativo durante treze anos. O mencionado instituto ressalta o perfil estratégico da referida obra, ou seja, a interligação de centros produtores ${ }^{4}$.

\section{Figura 1 - Linhas Ferroviárias Ativas e em Recuperação na Venezuela em} 2012

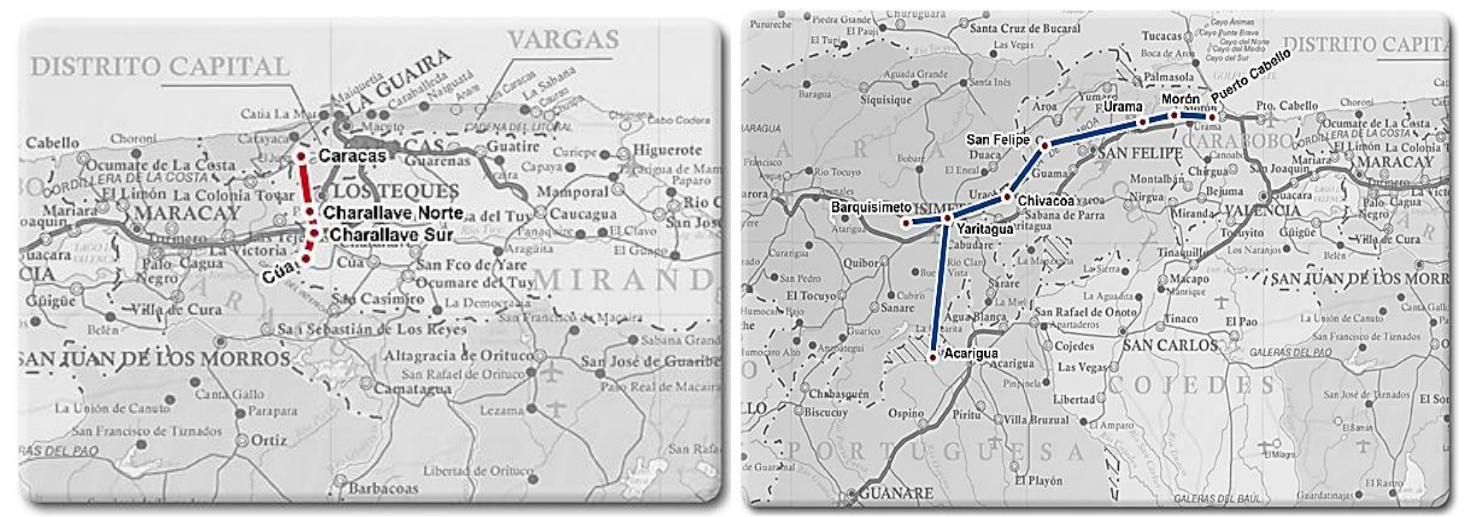

Fonte: IFE

A posição geográfica da Venezuela é indubitavelmente um obstáculo a uma maior integração física com os outros componentes do MERCOSUL. Até mesmo em relação ao Brasil, seu "parceiro" mais próximo, os desafios à integração não podem ser considerados irrelevantes, dada a extensa faixa de floresta presente na área fronteiriça. Além disso, através dos dados contidos na Figura 2, podemos constatar que a região fronteiriça mencionada também não possui trechos ferroviários no lado brasileiro. Como é possível constatar, as

\footnotetext{
4 Disponível em: http://www.ife.gob.ve/index.php/56
}

Ano 2014, N. 32 Vol 16, Pag. | Revista de Estudos Sociais 
provisões ferroviárias brasileiras ainda são caracterizadas pela prevalência de interligações entre centros produtores e regiões portuárias.

Figura 2 - Linhas Ferroviárias Ativas no Brasil em 2012

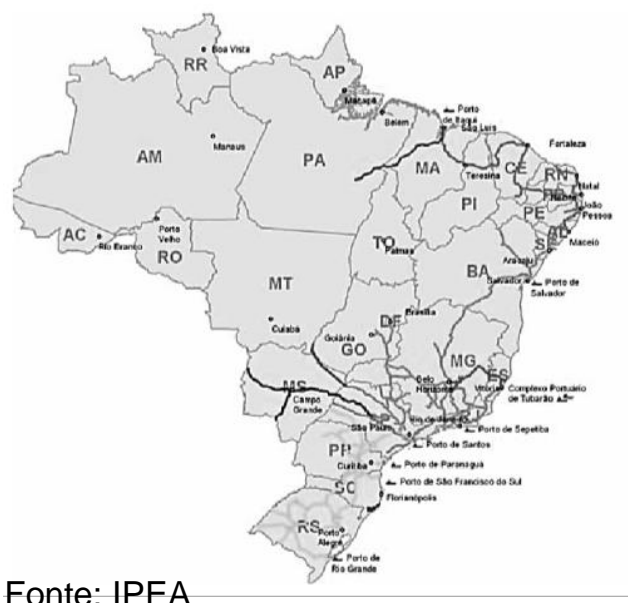

O desinteresse dos governos nacionais demonstrado ao longo dos anos em desenvolver esse meio de transporte pode ser considerado uma das principais causas que levaram à baixa provisão ferroviária existente atualmente nos países do MERCOSUL; nas últimas cinco décadas, a maior parte dos investimentos em infraestrutura de transportes terrestres foi destinada à construção de rodovias. A maioria das ferrovias presentes na região foi construída antes da II Guerra Mundial.

\subsection{Transporte Aeroviário}

Em relação à participação da América do Sul ao fluxo aéreo internacional, esta pode ser considerada ainda muito escassa. No período 2000-2008, a referida participação foi de apenas $7 \%$ nas decolagens totais e de $4 \%$ no volume de cargas transportadas, ambas com destinos internacionais (PERROTTI \& SÁNCHEZ, 2011). Em relação à assimetria existente entre os países que compõem o MERCOSUL, é possível verificar que a diferença entre Brasil e Paraguai, em termos de quantidade de $\mathrm{Km}$ voados por $\mathrm{Km}^{2}$ de território nacional, por exemplo, é bastante elevada e foi incrementada de modo significativo nos últimos anos (ver Gráfico 4).

Revista de Estudos Sociais | Ano 2014, N. 32, V. 16, Pag. 


\section{Gráfico 4- Quantidade de Km Voados por Km² de Território em 1980, 1990 e}

2005

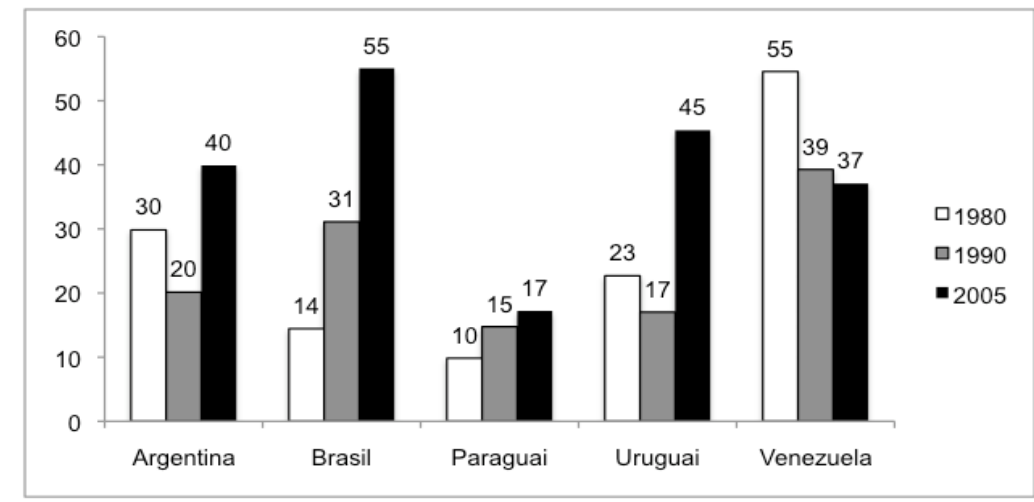

Fonte: Cepalstat

Entre os vinte aeroportos mais movimentados da América Latina (quantidade de voos decolados, ano 2010), nove são brasileiros, um argentino e outro venezuelano. Entre os vinte aeroportos com mais rápida expansão durante o período 2000-2010, encontramos a Argentina (Buenos Aires) na sexta colocação e o Brasil ocupando 9 posições (São Paulo GRU/ VCP, Rio de Janeiro, Brasília, Cuiabá, Belo Horizonte CNF/ PLU, Salvador, Curitiba). Por outro lado, entre os vinte aeroportos que apresentaram maior retração durante o mesmo período, quatro são venezuelanos; entre estes, está o aeroporto de Caracas (ALTA, 2011).

No caso do Brasil, o mencionado incremento pode ser considerado um dos fatores à base da deterioração, em termos qualitativos, dos serviços prestados em tal setor; entre os anos de 2010 e 2011, o número de acidentes aéreos no país aumentou em 41\%, segundo os dados do Centro de Investigação e Prevenção de Acidentes Aeronáuticos do Brasil (CENIPA).

O nível das disparidades regionais na provisão deste serviço também é muito acentuado. No Brasil, segundo o IPEA, cerca de $31 \%$ do total de passageiros e $48 \%$ do total de cargas transportadas por via aérea utilizam algum dos aeroportos localizados no estado de São Paulo. Em relação à participação por número de voos, as informações publicadas pela Latin America and Caribbean Air Transport Association (ALTA, 2011) revelam que $25 \%$ do total de decolagens no Brasil têm como origem São Paulo. Na Argentina, tal discrepância é ainda mais acentuada, dado que os dois aeroportos de Buenos Aires representam cerca $60 \%$ do total de decolagens do país. Em ralação ao Uruguai, segundo a Dirección Nacional de Transporte (DNT), a região de Montevidéu concentra quase $92 \%$ dos passageiros. 


\subsection{Transporte Marítimo}

A questão do transporte marítimo é de suma importância para os países do MERCOSUL, sobretudo pelos mesmos apresentarem vastas faixas litorâneas. Isso facilita o trânsito de mercadorias e pessoas, e tem relevância não apenas em termos econômicos, mas, principalmente ambientais. À exceção do Paraguai, todos os demais países possuem contato com o Oceano Atlântico, o que torna as transações do comércio internacional mais propícias de ocorrerem. Destacamos, nesse sentido, a relevância do transporte de cabotagem. No que se refere especificamente à Venezuela, vale destacar sua proximidade com os países da América Central e do mercado norte-americano.

De acordo com relatório conjunto de 2011 da Comissão Econômica para a América Latina e o Caribe (CEPAL) e do Instituto de Pesquisa Econômica Aplicada (IPEA), do Brasil,

"[o] setor portuário passou por reformas que geraram consequências positivas. A incorporação de agentes econômicos privados, como operadores diretos, propiciou grandes investimentos e profundas mudanças nos regimes de propriedade, fato que conduziu a uma grande queda nos preços de operação portuária e a uma marcante melhora no desempenho operacional, medido tanto em tempo quanto na qualidade da prestação (...) [n]o geral, os portos foram concessionados ao setor privado, usando amplamente o conceito de landlord, segundo o qual o Estado conserva a propriedade dos ativos e concessiona a operação ao setor privado" (CEPAL, 2008 in SANTIAGO, 2011, p. 49).

No entanto, é necessário ter em mente que, igualmente aos demais modais, as assimetrias também são muitas entre os portos entre os países do MERCOSUL e, além disso, dentro de cada um desses países. Sendo assim, "alguns apresentam maior capacidade instalada apta para operação com transporte multimodal e outros apresentam grandes déficits. Perante a situação econômico-financeira e a realidade institucional dos portos dos países da região, o serviço apresenta algumas características preocupantes" (SANTIAGO, 2011, p.52). Nesse sentido, as maiores queixas referem-se "à conservação e à manutenção das áreas comuns, ao calado e às limitações nos canais de acesso aos terminais e à falta de equipamentos intermodais. $O$ problema de acesso terrestre aos portos e às externalidades que causam sobre as cidades são outros aspectos fundamentais no que se refere aos portos" (SANTIAGO, 2011, p.52).

A Tabela 3 apresenta a tendência de superávit na balança comercial de bens do MERCOSUL transacionados por via marítima. Apesar de os dados desagregados por país e modal serem bastante limitados, sabe-se que existe uma forte assimetria entre a parcela de cada um deles no resultado agregado, com forte destaque para Argentina, Brasil e Venezuela.

Revista de Estudos Sociais | Ano 2014, N. 32, V. 16, Pag. 
Tabela 3 - Evolução das Exportações e Importações por transporte marítimo no MERCOSUL, 2008-2013 (Bi US\$ FOB)

\begin{tabular}{|l|l|l|l|}
\hline Período & $\begin{array}{l}\text { Exportações } \\
\text { (Bi US\$ FOB) }\end{array}$ & $\begin{array}{l}\text { Importações } \\
\text { (Bi US\$ FOB) }\end{array}$ & $\begin{array}{l}\text { Balança } \\
\text { (Bi US\$ FOB) }\end{array}$ \\
\hline 2008 & 9.044 & 7.548 & 1.496 \\
\hline 2009 & 5.310 & 6.412 & -1.102 \\
\hline 2010 & 8.642 & 8.299 & 342 \\
\hline 2011 & 11.221 & 10.155 & 1.066 \\
\hline 2012 & 9.008 & 9.605 & -597 \\
\hline $2013^{*}$ & 14.250 & 9.883 & 4.367 \\
\hline
\end{tabular}

Fonte: Elaboração própria com base em ALICEWeb; * inclui Venezuela.

Especificamente no caso argentino, a grande maioria dos portos operava com práticas ineficientes e, portanto, incorre em custos desnecessários, existindo, ainda, conflitos de poder e responsabilidade entre as múltiplas agências reguladoras. Contudo, conforme mencionado acima, é apenas na década de 1990' s, com a instauração de um plano de ajuste estrutural que o país passa a se beneficiar de relevantes transformações econômicas e institucionais.

Em outras palavras, o que ocorre é a transferência dos serviços e da infraestrutura portuária, que era histórica e tradicionalmente de propriedade e administração pública, para a iniciativa privada. Houve, na altura, a assinatura da Lei dos Portos (№ 24.093), que (i) introduz diversas reformas nesse setor; (ii) permite a privatização da atividade portuária; e (iii) dá início à modernização do setor (DOER, 2011). Ademais, os principais portos nacionais são o de Rosario, Buenos Aires, Bahia Blanca, Mar del Plata, Quequén, San Antonio Oeste, Puerto Madyn, Comodoro Rivadavia, San Julian, Rio Gallegos, Ushuaia.

É digno de nota o fato de que a maior parte do comércio argentino se dá por meio das vias fluvial e marítima, contudo, mesmo depois dos avanços da década passada, ainda existem alguns inconvenientes à adequada exploração da infraestrutura portuária nacional. Um dos exemplos se deve à falta de portos de águas profundas para receber os grandes barcos do transporte marítimo internacional; o mais próximo disso está o porto de Buenos Aires.

Já no que se refere ao caso brasileiro, temos que em 2007 foi criado no país a Secretaria Especial de Portos (SEP), cujo principal objetivo relaciona-se à formulação de políticas e diretrizes para a promoção do setor portuário brasileiro. Além disso, a Secretaria participa do planejamento estratégico e da aprovação dos planos das autoridades portuárias, incluindo a preparação de planos estratégicos. Por fim, a secretaria promove políticas específicas destinadas a melhorar e tornar mais competitiva a atividade dos portos nacionais. Além disso, em 2013, houve a promulgação da Nova Lei dos Portos, que pretende modernizar os portos brasileiros. Ela estabelece novos critérios para a exploração e arrendamento (por meio de contratos de cessão para uso) para a iniciativa privada de terminais de movimentação de carga em portos públicos. Além disso, as novas regras facilitam a instalação de novos terminais portuários privados. 
Figura 3 - Localização dos Portos Brasileiros

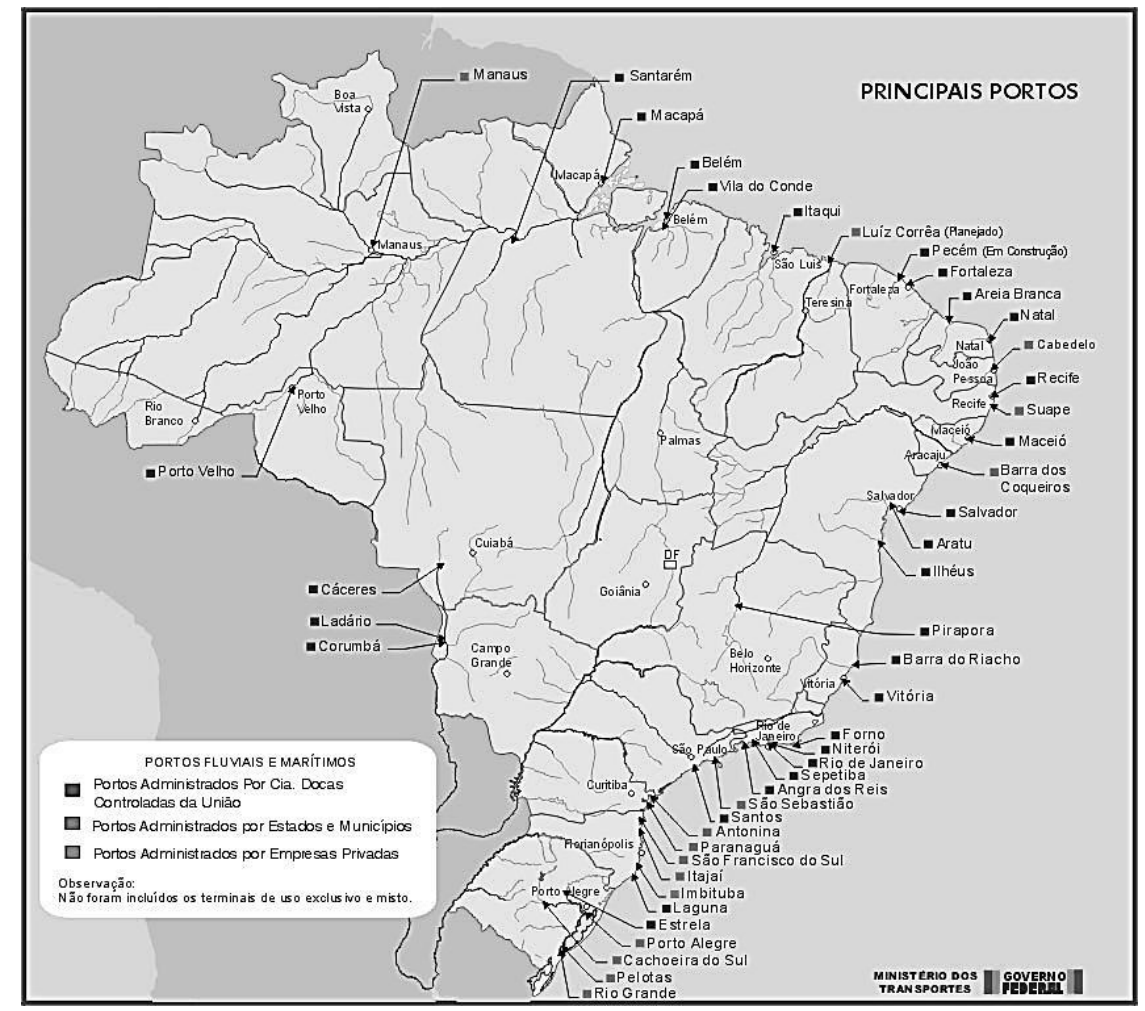

Fonte: ANTAQ

Dados do Anuário Estatístico de 2013 da Agência Nacional de Transporte Aquaviários (ANTAQ) evidenciam que, em 2013, a carga movimentada em portos e Terminais de Uso Privativo (TUPs) foi de US\$ 931 bilhões de dólares. Do total do valor das exportações, $84 \%$ correspondem ao transporte marítimo e, no que se refere à exportação em toneladas, $98 \%$.

Se, por outro lado, analisarmos apenas o período de 2011, percebemos que os principais portos organizados são, respectivamente, o de Santos, Itaguaí e Paranaguá e que, se fizermos a mesma análise em termos de movimentação em valor para os terminais privativos, temos CVRD Tubarão, Ponta da Madeira e Almirante Barroso, respectivamente.

Revista de Estudos Sociais | Ano 2014, N. 32, V. 16, Pag. 


\section{Gráfico 5 - Evolução da movimentação portuária dos principais Portos e TUPs, 2009-13 (em milhões de toneladas)}

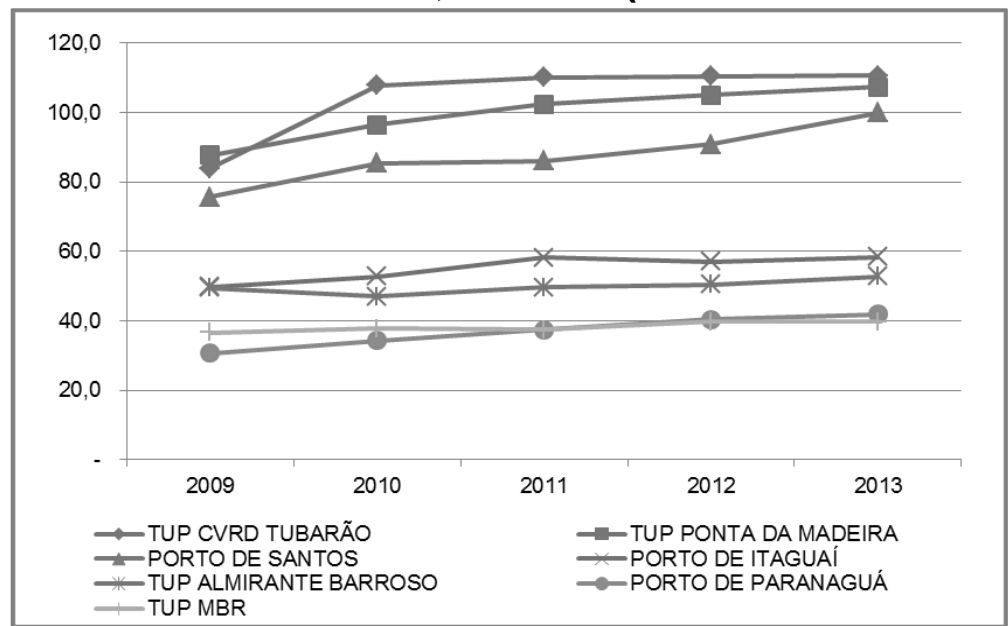

Fonte: Elaboração própria com base em ANTAQ (2013)

Ainda de acordo com o relatório da ANTAQ, de 2013, temos que no caso da movimentação dos portos, $39,6 \%$ de um total de 834 bilhões de toneladas corresponde a minério de ferro, 23,1\% combustíveis e óleos minerais, $6 \%$ soja e $4,3 \%$ bauxita.

No caso do Paraguai, temos, de acordo com a Administración Nacional de Navegación y Puertos Paraguay (ANNP), que os principais portos nacionais são o Puerto de Villeta, Puerto Asunción, Puerto Concepción e o Puerto Encarnación.

\section{Figura 4 - Zona de Atividade Logística do Paraguai}

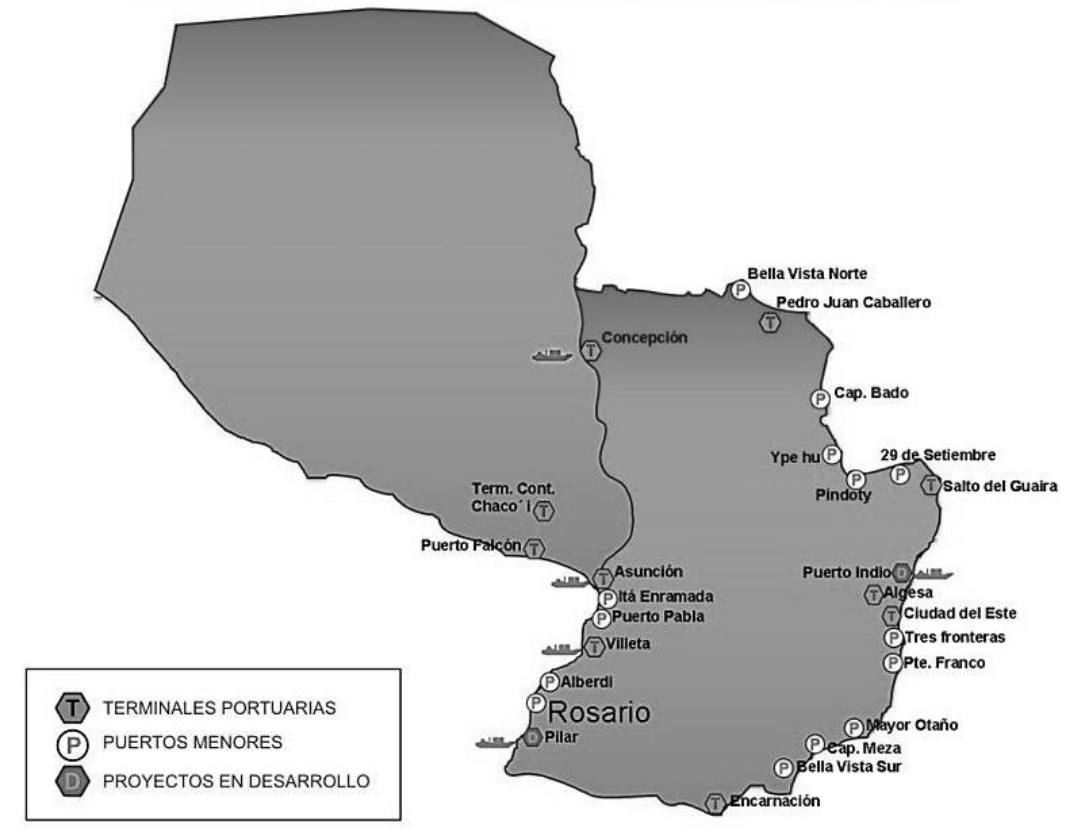

Fonte: ANNP

Já no Uruguai, temos que o país movimentou 15,5 milhões de toneladas Ano 2014, N. 32 Vol 16, Pag. | Revista de Estudos Sociais 
em 2007, entre 18 portos, com carga média de 941 mil toneladas. De acordo com a Aministración Nacional de Puertos (ANP), os principais portos nacionais são os de Montevideo, Nueva Palmira, Fray Bentos, Colonia, Juan Lacaze, Paysandú e Salto. Os gráficos abaixo apresentam detalhamento da movimentação do transporte marítimo de contêineres e por carga no país, apresentando os últimos dados publicados pela ANP.

\section{Gráfico 6 - Evolução da movimentação Gráfico 7 - Evolução da movimentação de Contêineres TEUs, 2009-2013 por carga, 2009-2013} (em mil ton)
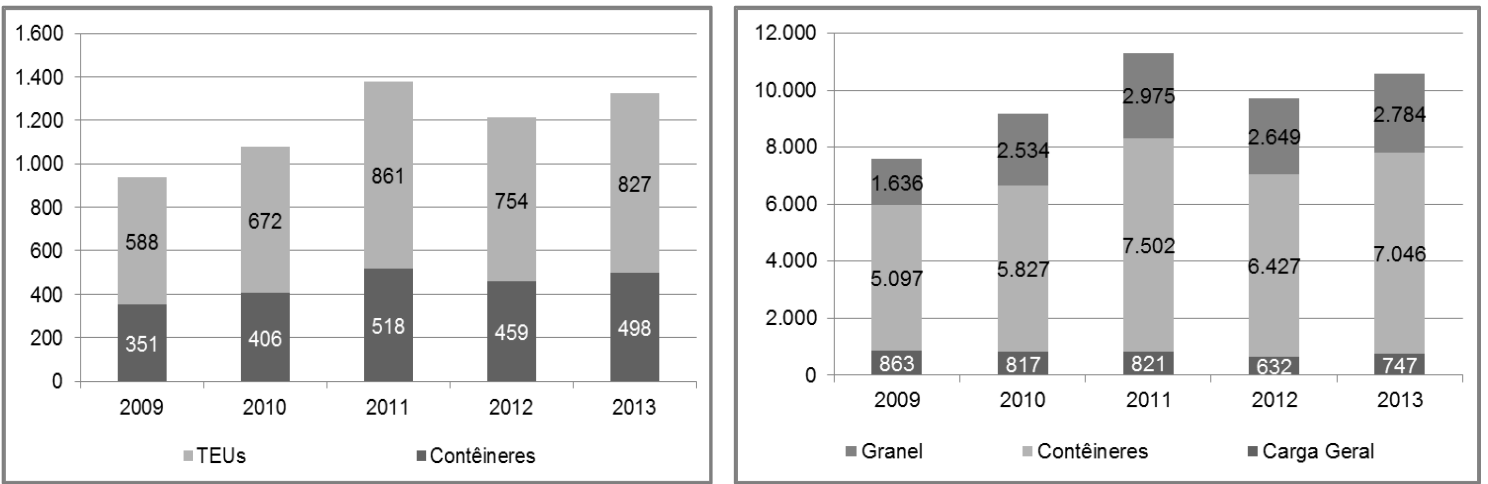

Fonte: ANP

No que se refere à Venezuela, a Asociación de Logística de Venezuela (ALV) afirma que $90 \%$ do comercio do país se dá por via marítima, sendo cerca de $60 \%$, para granéis líquidos e sólidos, e $30 \%$ de contêineres. Em 2010, por exemplo, a movimentação de contêiner alcançou a carga de 560 Mi de TEUs. Vale ressaltar, no entanto, que a recessão, que começou em outubro de 2008 afetou fortemente as transações comerciais do país, porém já apresenta retorno desde o início de 2010.

A Venezuela possui $860.000 \mathrm{Km}^{2}$ de superfície marítima navegável, o que fica representado peo mar do Caribe e pelo Oceano Atlântico. Seus portos mais importantes são o Puerto Cabello (Edo. Carabobo), Puerto de La Guaira (Edo. Vargas), Puerto de Maracaibo (Edo. Zulia) e o Puerto Pesquero Internacional de Güiria (Edo. Sucre).

Contudo, longos períodos de tempo de espera nos portos, associados à ineficiência dos procedimentos e infraestrutura relativamente ultrapassada, leva ao aumento de custos associados, ao aumento dos fretes acima da média e, consequentemente, à baixa produtividade dos portos venezuelanos e ao alto congestionamento nos mesmos.

Revista de Estudos Sociais | Ano 2014, N. 32, V. 16, Pag. 


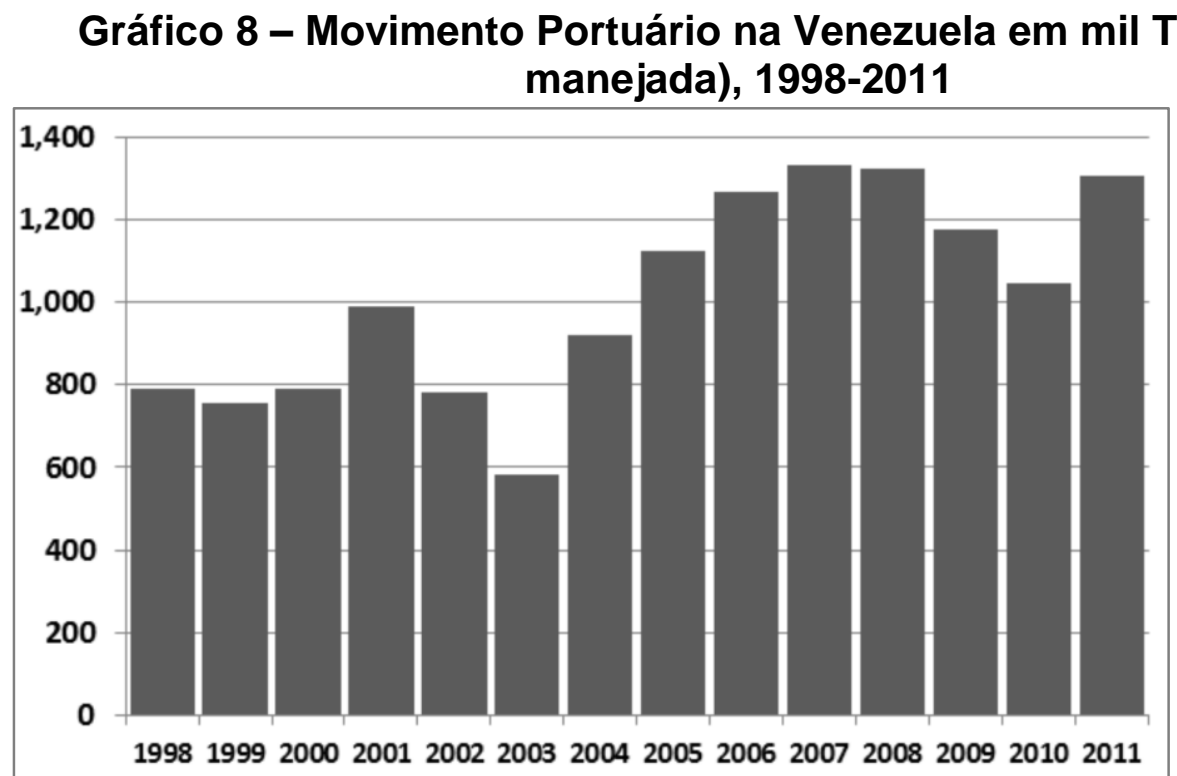

Fonte: CEPAL

Tabela 4 - Movimentação de Carga por Principais Portos em mil TEUS (carga manejada), 2001-2011

\begin{tabular}{|l|l|l|l|l|l|l|l|l|l|l|l|}
\hline PORTO & $\mathbf{2 0 0 1}$ & $\mathbf{2 0 0 2}$ & $\mathbf{2 0 0 3}$ & $\mathbf{2 0 0 4}$ & $\mathbf{2 0 0 5}$ & $\mathbf{2 0 0 6}$ & $\mathbf{2 0 0 7}$ & $\mathbf{2 0 0 8}$ & $\mathbf{2 0 0 9}$ & $\mathbf{2 0 1 0}$ & $\mathbf{2 0 1 1}$ \\
\hline P. Cabello & 621 & 506 & 380 & 598 & 734 & 844 & 832 & 809 & 716 & 630 & 722 \\
\hline La Guaiara & 304 & 216 & 151 & 261 & 328 & 342 & 422 & 437 & 377 & 334 & 467 \\
\hline Maracaibo & 66 & 31 & 24 & 29 & 27 & 32 & 38 & 37 & 42 & 42 & 58 \\
\hline Guanta & - & 28 & 28 & 33 & 37 & 49 & 40 & 42 & 41 & 42 & 59 \\
\hline Total & 991 & 781 & 583 & 921 & 1.126 & 1.267 & 1.332 & 1.325 & 1.175 & 1.048 & 1.306 \\
\hline
\end{tabular}

Fonte: CEPAL

De janeiro a maio de 2014, Puerto Cabello foi a principal aduana de importação e representou $44 \%$ do total. Por sua vez, La Guaira, Maiquetía e Maracaibo representaram $34 \%$ de total. Vale destacar que as importações totais do período foram 20\% inferiores ao mesmo período de 2013 (INE, 2014; ALV, 2014).

\section{ENERGIA}

É interessante começar nossa análise do setor enérgico destacando que os anos 1990' s - assim como para o caso dos transportes - constituíram um divisor de águas no que se refere a reformas energéticas que atingiram a maioria dos países da América Latina e do Caribe. Ainda que haja certo alinhamento na tomada de decisões entre tais países nessa década, é necessário destacar que existem diferenças substanciais no que se refere à orientação e à distribuição de responsabilidades entre o Estado e o setor privado. 
De acordo com relatório conjunto CEPAL/IPEA (2011), "[o]s elementos específicos que os países selecionaram para levar a cabo o processo de reforma energética em geral - e elétrica em particular - podem ser classificados em fatores exógenos, como: i) dívida externa e balanço de pagamentos; ii) estabilidade macroeconômica; iii) desenvolvimento dos mercados de capital internos; e iv) necessidade de investimento na expansão dos sistemas. Entre os fatores endógenos merecem destaque: i) a necessidade de introduzir competitividade nos segmentos ou mercados nos quais é possível; e ii) recuperar a eficiência dos sistemas elétricos (SANTIAGO, 2011).

Sendo assim, e após mais de 10 (dez) anos da reforma do setor elétrico e, em determinados casos, mais de 20 (vinte) anos, percebe-se que houve claro progresso no funcionamento do setor, muito embora tenha havido, a reboque, certa paralisação na dinâmica que, aparentemente, estaria indicando a necessidade de revisar as bases desse processo e eventualmente corrigir ou completar aspectos do marco regulatório (MALDONADO, 2004).

Mais uma vez, o problema na coleta de dados nos alcança e, pela inexistência ou precariedade dos mesmos, praticamente não há informações sistemáticas sobre índice de eletrificação, contudo, dada a alta parcela da população urbana, observa-se uma alta participação de população atendida por rede elétrica. De acordo com Santiago (2011), a maior parte dos países da região latino-americana supera $80 \%$ de famílias com acesso à energia elétrica.

No entanto, "[a]pesar dos benefícios e da evidente melhora de eficiência dos sistemas elétricos em conjunto, não se obteve avanços significativos no processo de interconexão em nível regional". Dessa forma, de acordo com o mesmo relatório,

"para avançar nesse processo, é necessário, entre outros, estabelecer acordos entre países que permitam homogeneizar aspectos básicos da regulação, por exemplo, a remuneração das redes de transmissão; identificar condições de complementaridade que permitam explorar os recursos de cada país, em períodos chuvosos, normais ou secos; definir as condições comerciais e de operação tanto para as transações de curto prazo quanto para as de longo prazo; composição, função, autoridade da entidade responsável pela operação e despacho do sistema comum; normalização dos requerimentos que regerão a confiabilidade dos sistemas." (SANTIAGO, 2011, p.24)

Para representar o caso brasileiro, o Gráfico 9 e a Tabela 5 evidenciam os diferentes energéticos e usos, com base nos dados do último Balanço Energético Nacional (BEN), publicado pela Empresa de Pesquisa Energética (EPE).

Revista de Estudos Sociais | Ano 2014, N. 32, V. 16, Pag. 


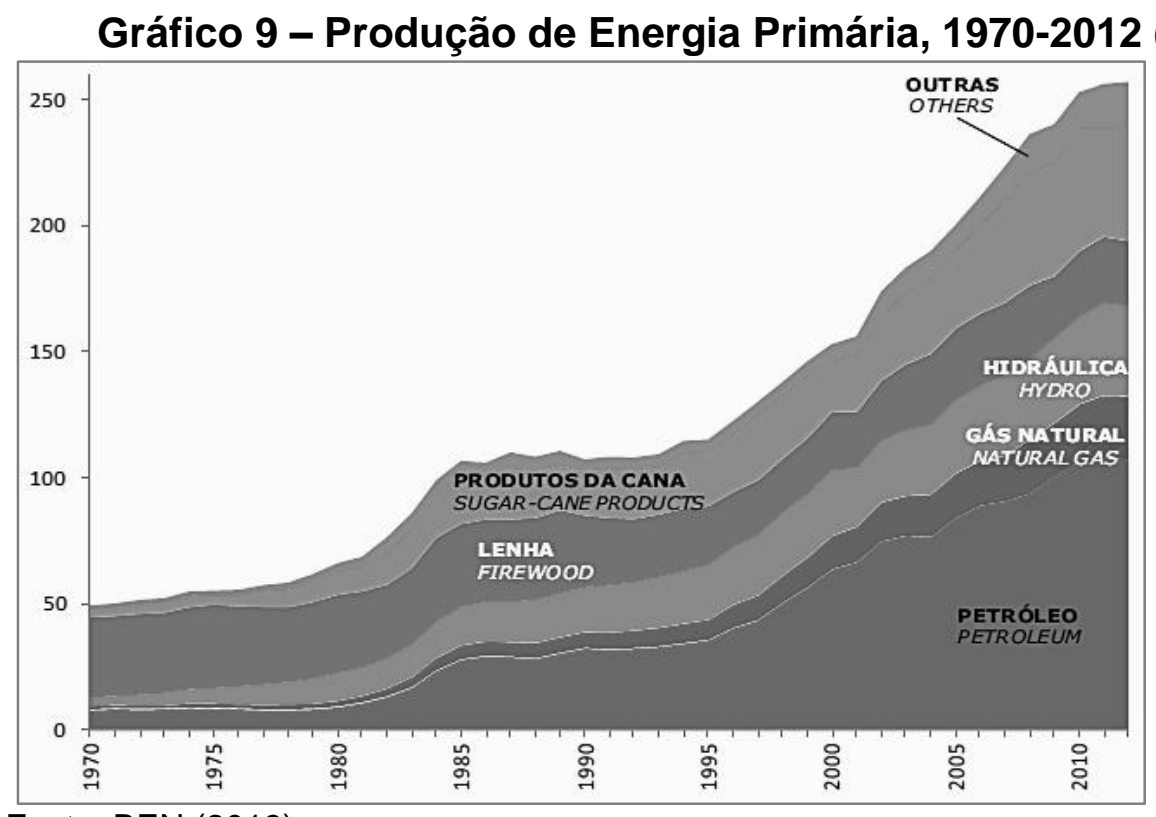

Fonte: BEN (2013)

Tabela 5 - Consumo Final por Setor, 2008-12 (em $10^{3}$ tep)

\begin{tabular}{|l|l|l|l|l|l|}
\hline SETOR\ANO & $\mathbf{2 0 0 8}$ & $\mathbf{2 0 0 9}$ & $\mathbf{2 0 1 0}$ & $\mathbf{2 0 1 1}$ & $\mathbf{2 0 1 2}$ \\
\hline CONSUMO FINAL FINAL NÃO- & 226.215 & 220.732 & 241.194 & 245.860 & 253.422 \\
\hline $\begin{array}{l}\text { CONSUMO } \\
\text { ENERGÉTICO }\end{array}$ & 14.676 & 14.921 & 17.686 & 16.837 & 16.678 \\
\hline CONSUMO FINAL ENERGÉTICO & 211.538 & 205.811 & 223.508 & 229.023 & 236.744 \\
\hline SETOR ENERGÉTICO & 24.679 & 23.916 & 24.263 & 22.171 & 22.888 \\
\hline RESIDENCIAL & 22.738 & 23.129 & 23.562 & 23.267 & 23.761 \\
\hline COMERCIAL & 6.190 & 6.335 & 6.731 & 7.124 & 7.710 \\
\hline PÚBLICO & 3.622 & 3.648 & 3.636 & 3.758 & 3.749 \\
\hline AGROPECUÁRIO & 9.911 & 9.553 & 10.029 & 9.999 & 10.362 \\
\hline TRANSPORTES & 62.829 & 63.041 & 69.720 & 73.989 & 79.308 \\
\hline INDUSTRIAL & 81.570 & 76.189 & 85.567 & 88.716 & 88.966 \\
\hline
\end{tabular}

Fonte: BEN (2013)

O caso do Paraguai é interessante, pois este é o maior país em termos de geração hidroelétrica per capita do mundo, ou seja, percebemos, assim, a importância dessa fonte na produção de energia nacional. No entanto, o mesmo não ocorre quando tratamos de seu consumo, dado que representa apenas $15 \%$ do total das fontes de energia do país. A biomassa e os combustíveis são os recursos energéticos mais utilizados no consumo doméstico e industrial no mencionado país (MASI, 2011). A Tabela 6 a seguir destaca a relevância das binacionais, com especial foco em Itaipu. 
Tabela 6 - Geração e Consumo de Energia Hidroelétrica no Paraguai em 2010

\begin{tabular}{|l|l|l|l|l|}
\hline Fontes & $\begin{array}{l}\text { Geração total } \\
\text { (GWh) }^{*}\end{array}$ & $\begin{array}{l}\text { Geração disponível } \\
(\mathbf{G W h})^{\star *}\end{array}$ & $\begin{array}{l}\text { Consumo total } \\
\text { (GWh) }\end{array}$ & $\begin{array}{l}\text { Consumo (\%) } \\
* \star \star\end{array}$ \\
\hline Itaipu & 90.358 & 45.179 & 7.656 & 4,0 \\
\hline Yacyreta & 17.156 & 8.578 & 1.887 & 3,5 \\
\hline Acaray & 1.020 & 927 & 927 & 1,7 \\
\hline Total & 108.534 & 54.684 & 10.470 & 19,2 \\
\hline
\end{tabular}

Fonte: Masi, 2011; * Média anual; ** Tendo em conta que somente $50 \%$ da geração de Itaipu e Yacyreta; ${ }^{* * *}$ Consumo de GWh de cada represa sobre o total de geração disponível.

O Paraguai tem cerca de $5.000 \mathrm{Km}$ linhas de transmissão de baixa potência (66 a $220 \mathrm{~kW}$ ) e apenas $16 \mathrm{Km}$ de linhas de $500 \mathrm{kV}$ (alta potência), estando em último lugar no ranking da América do Sul em termos de linhas de transmissão de medidos por 500 kV / GWh, estando, inclusive, abaixo de países como Chile e Uruguai, que produzem muito menos energia hidroelétrica. Sendo assim, com a ausência de linhas de transmissão de alta potência e uma demanda média de energia crescente ao redor de 5\% nos últimos 10 (dez) anos e de $8 \%$ nos últimos 05 (cinco) anos, o sistema elétrico paraguaio está iniciando uma fase difícil manifestada por falhas frequentes no sistema, com dano correspondente a usuários individuais e grupos (MASI, 2011).

Gráfico 10- Oferta e Demanda de Energia Elétrica no Paraguai, 1994-2014*

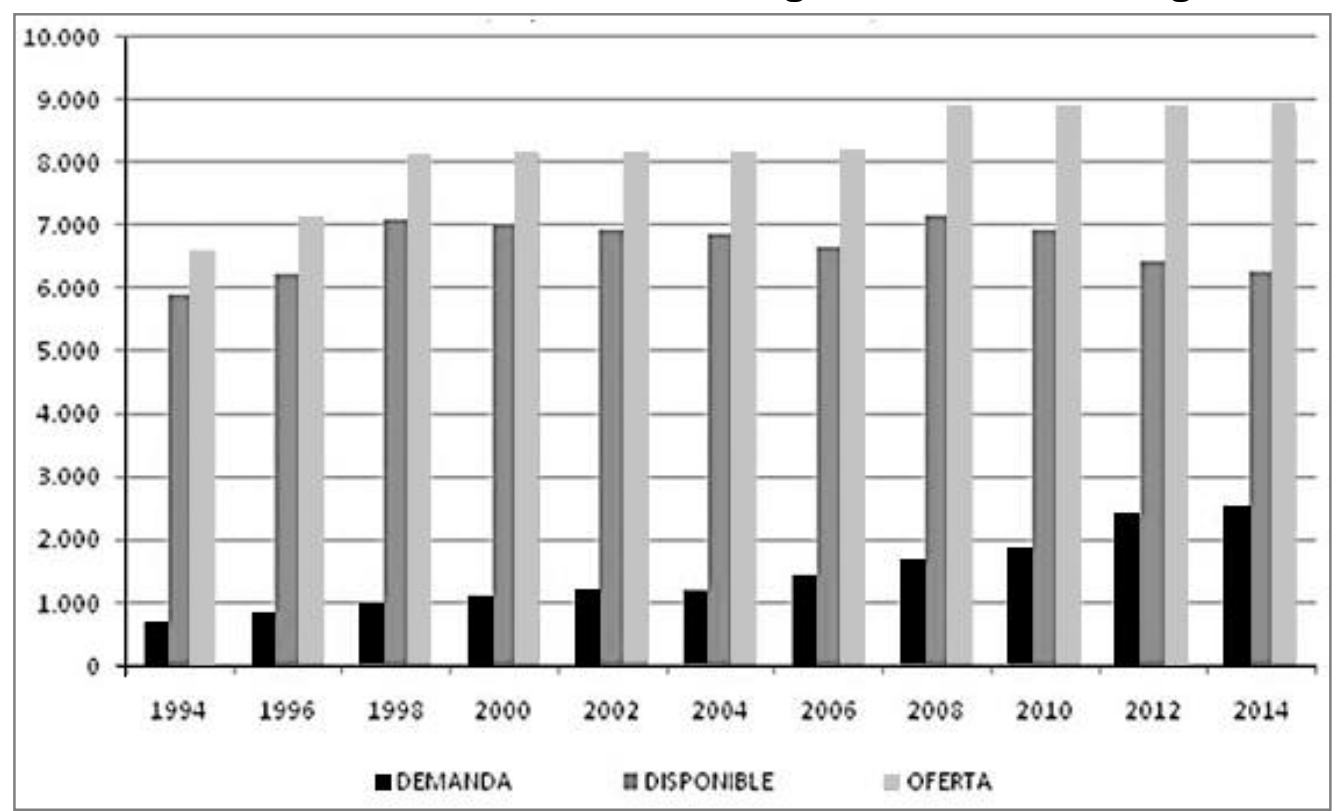

Fonte: ANDE; * até maio.

O Sistema Interligado Nacional (SIN) é abastecido, sobretudo por centrais hidroelétricas.

Itaipu apresenta 20 (vinte) geradores, cada um com uma capacidade nominal de $700 \mathrm{MW}$ (10 pertencem ao Paraguai e 10 ao Brasil). A potência disponível para o país é de $7.000 \mathrm{MW}$ e se encontra, atualmente, em operação. Acaray possui 04 (quatro) geradores, cada um com uma capacidade nominal de $50 \mathrm{MW}$ (pertence à Administracion Nacional de Electricidad - ANDE). Sua

Revista de Estudos Sociais | Ano 2014, N. 32, V. 16, Pag. 
potência disponível é de $200 \mathrm{MW}$ e encontra-se em operação, desenvolvendo trabalhos de restauração e modernização dos principais equipamentos. Já Yacyretá possui 20 geradores, cada um com uma capacidade nominal de 172,5 MW (10 pertencem ao Paraguai e 10 à Argentina). Sua potência disponível é de $1.600 \mathrm{MW}$ para o país e apresenta, atualmente, 20 (vinte) unidades. Em menor escala, existe Bahia Negra (0,565 MW), Fuerte Olimpo (0,5 MW), Pedro J. Caballero (3 MW) e Salto del Gairá (20,875 MW).

Além da geração hidráulica mencionada, a ANDE conta com os seguintes grupos de geração térmica: San Carlos (0,08 MW), Bahía Negra $(0,28 \mathrm{MW})$, La Patria (0,28 MW), Mcal. Estigarribia (1,36 MW), Pedro J. Caballero (2,8 MW) e Sajonia (33,7 MW).

A matriz energética do Uruguai pode ser apresentada da seguinte forma:

a) Hidroeletricidade: Represa de Salto Grande no rio Uruguai: 1.000 MW; e Represas do Rio Negro: 500 MW.

b) Térmicas: Unidades da central batlle: $300 \mathrm{MW}$; Punta del Tigre: 300 MW; e Gas Oil em La Tablada: 200 MW;

c) Eólica: $20 \mathrm{MW}$ de UTE e há quase pronto uns $80 \mathrm{MW}$ a mais de setores privados.

d) Geração Distribuída (privada): chegando a 10 produtores, quase $200 \mathrm{MW}$ instalados se somarmos a Botnia (90 MW total - ainda que só venda $30 \mathrm{MW}$ a UTE), $80 \mathrm{MW}$ em total de compra em modalidade, em geral do tipo spot.

Tabela 7- Usinas, Fontes, Potências Instaladas e Autorizadas no Uruguai em 2013

\begin{tabular}{|c|c|c|c|c|c|}
\hline \multirow[b]{2}{*}{ PARTICIPANTE } & \multirow[b]{2}{*}{ FUENTE } & \multirow{2}{*}{$\begin{array}{r}\text { POTENCIA } \\
\text { INSTALADA }\end{array}$} & \multirow{2}{*}{$\begin{array}{c}\text { POTENCIA } \\
\text { AUTORIZADA } \\
\text { POR EL PODER } \\
\text { EJECUTIVO }\end{array}$} & \multicolumn{2}{|c|}{ ACTIVIDAD EN EL MMEE } \\
\hline & & & & $\begin{array}{l}\text { Mercado de } \\
\text { Contratos a } \\
\text { Término }\end{array}$ & Mercado Spot \\
\hline \multicolumn{6}{|c|}{ EN SERVICIO } \\
\hline UTE & $\begin{array}{l}\text { HIDRAULICA- } \\
\text { TÉRMICA-EÓLICA }\end{array}$ & $1572 \mathrm{MW}$ & & $\nabla$ & \\
\hline CTMSG Delegación Uruguaya & HIDRÁULICA & $945 \mathrm{MW}$ & & $\nu$ & \\
\hline AGROLAND S.A. & EÓLICA & $0,3 \mathrm{MW}$ & $0,3 \mathrm{MW}$ & $\nu$ & \\
\hline BIOENER S.A. & BIOMASA & $12 \mathrm{MW}$ & $12 \mathrm{MW}$ & $\nabla$ & 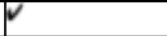 \\
\hline FENIROL S.A. - ERT & BIOMASA & $10 \mathrm{MW}$ & $10 \mathrm{MW}$ & $\nabla$ & $\nabla$ \\
\hline GALOFER S.A. & BIOMASA & $14 \mathrm{MW}$ & $14 \mathrm{MW}$ & $\nabla$ & $\nabla$ \\
\hline LAS ROSAS - I.M.MALDONADO & $\begin{array}{l}\text { BIOMASA/RELLEN } \\
\text { O SANITARIO }\end{array}$ & $1,2 \mathrm{MW}$ & $1,2 \mathrm{MW}$ & $\nabla$ & \\
\hline LIDERDAT S.A. & BIOMASA & $5 \mathrm{MW}$ & $5 \mathrm{MW}$ & & $\nabla$ \\
\hline NUEVO MANANTIAL S.A. & EÓLICA & $18,05 \mathrm{MW}$ & $18,05 \mathrm{MW}$ & $\nabla$ & 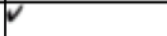 \\
\hline UPM S.A. & BIOMASA & $161 \mathrm{MW}$ & $161 \mathrm{MW}$ & $\nabla$ & \\
\hline WEYERHAEUSER PRODUCTOS S.A. & BIOMASA & $12 \mathrm{MW}$ & $12 \mathrm{MW}$ & $\nabla$ & \\
\hline ZENDALEATHER S.A. & GAS & $3,2 \mathrm{MW}$ & $3,2 \mathrm{MW}$ & & $\nu$ \\
\hline ALUR S.A. & BIOMASA & $10 \mathrm{MW}$ & $10 \mathrm{MW}$ & $\nabla$ & \\
\hline KENTILUX S.A. & EÓLICA & $17,2 \mathrm{MW}$ & $17,2 \mathrm{MW}$ & $\nabla$ & \\
\hline PONLAR S.A. & BIOMASA & $7,5 \mathrm{MW}$ & $7,5 \mathrm{MW}$ & $\nabla$ & $V$ \\
\hline ENGRAW S.A. & EÓLICA & $3,6 \mathrm{MW}$ & $3,6 \mathrm{MW}$ & & $\nabla$ \\
\hline LAVADERO DE LANAS BLENGIO S.A. & EÓLICA & $1,8 \mathrm{MW}$ & $1,8 \mathrm{MW}$ & & $V$ \\
\hline R DEL SUR S.A. & EÓLICA & $50 \mathrm{MW}$ & $50 \mathrm{MW}$ & $\nabla$ & \\
\hline PALMATIR S.A. & EÓLICA & $50 \mathrm{MW}$ & $50 \mathrm{MW}$ & $\nabla$ & \\
\hline
\end{tabular}

Fonte: ADME 


\section{Gráfico 11 - Abastecimento da demanda uruguaia por fonte em 2011}

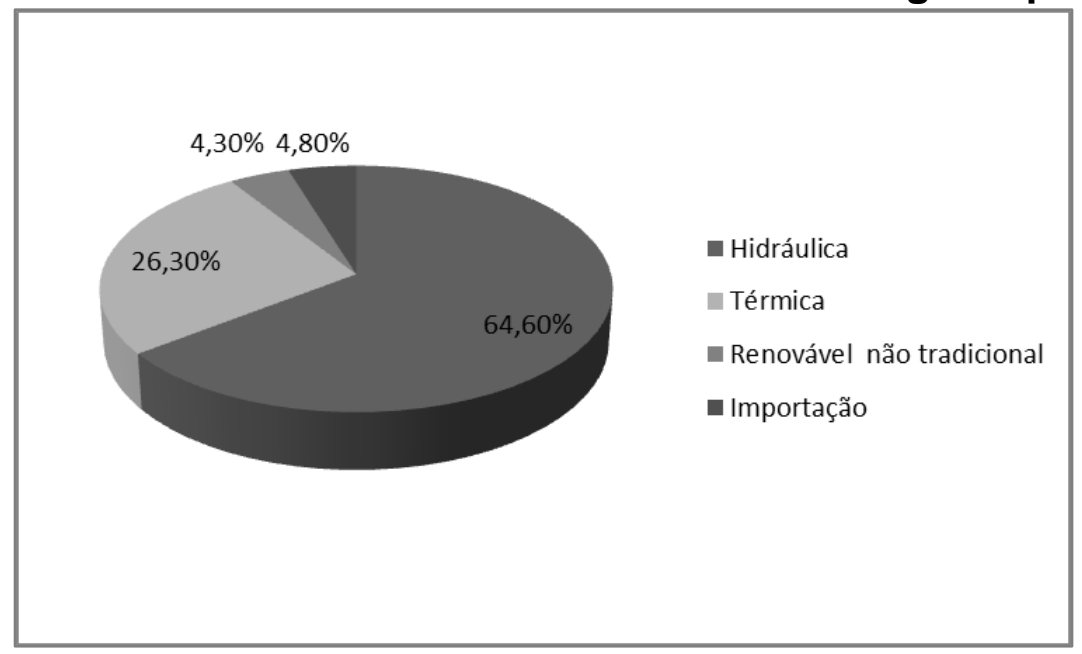

Fonte: ADME

No caso do Uruguai, percebemos pela Tabela 7 e pelo Gráfico 11 que a energia do país é fortemente concentrada na hidroeletricidade, correspondendo a $64,6 \%$. Pouco mais de $1 / 4$ (um quarto) da matriz decorre de térmicas, o que indica um alto grau de participação de energias suja no país.

Já na Venezuela, apresentamos as Figuras 5 e 6, que não apenas apresentam as demandas máximas e a geração, indicando o valor das importações, mas capacidade instalada e a relevâncias das térmicas no parque. Aproximadamente $50 \%$ da capacidade instalda venezuelana vem de usinas termelétricas, o que indica um perfil elétrico "sujo" do ponto de vista ambiental.

Figura 5 - Sistema Elétrico da Venezuela em 2012 (em MW)

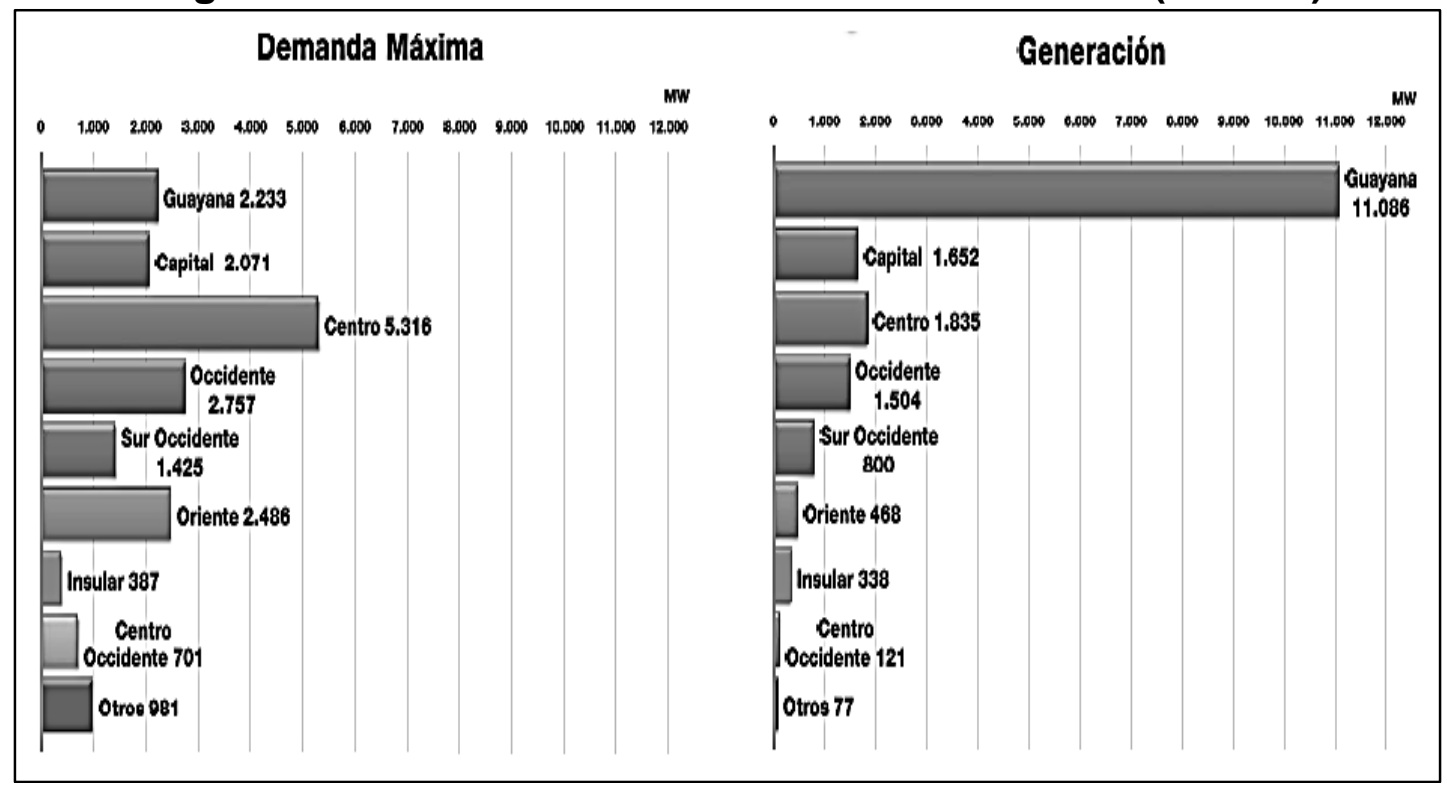

Fonte: Anuario Estadístico MPPEE, 2013

Revista de Estudos Sociais | Ano 2014, N. 32, V. 16, Pag. 
Figura 6 - Capacidade Instalada, Térmicas e Outras Fontes em 2012 (em MW)

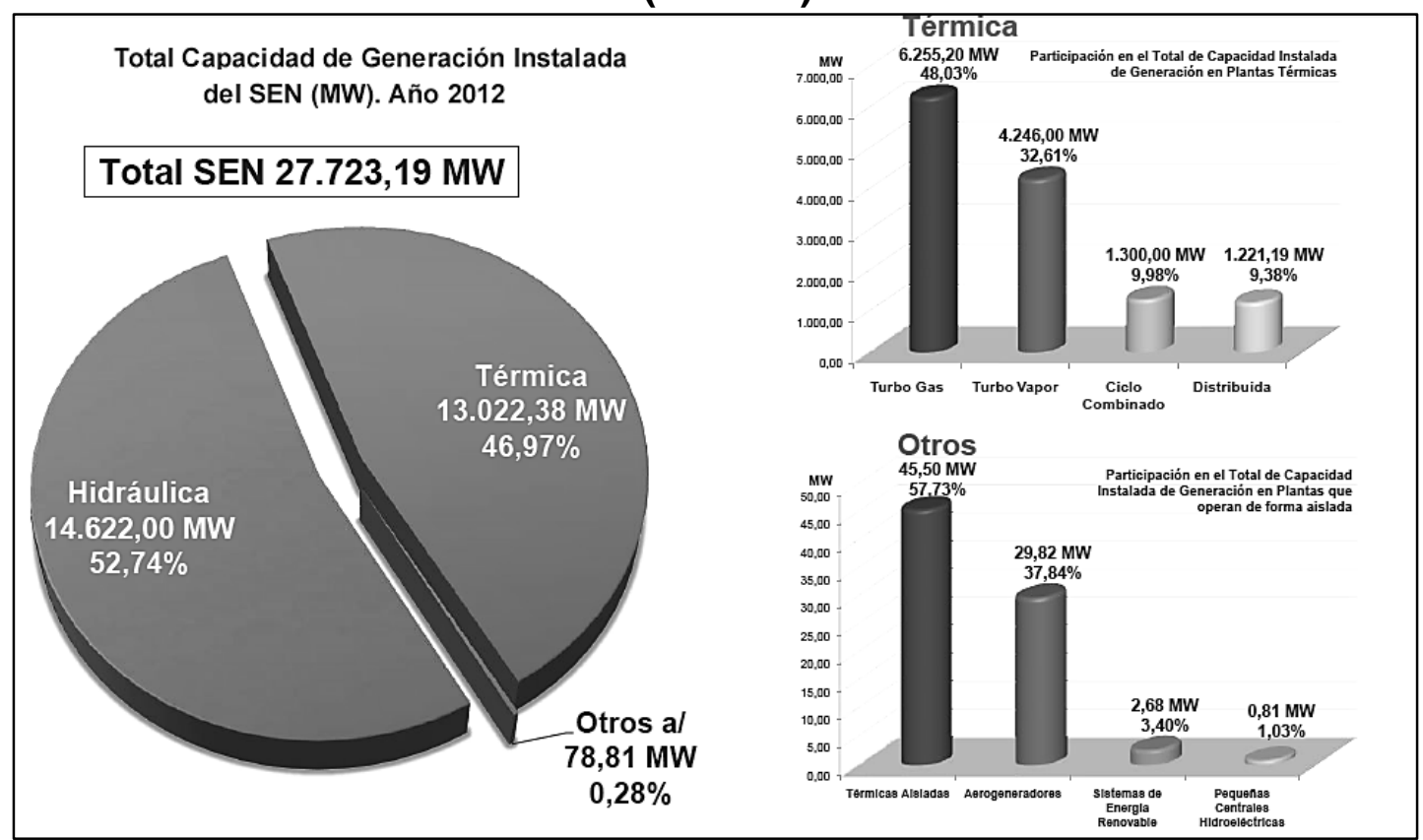

Fonte: Anuario Estadístico MPPEE, 2013

No caso da Venezuela, bem como nos casos do Brasil e da Argentina, temos claros e recentes exemplos de crises de abastecimento energético, que levaram a um longo debate acerca da matriz energética desses países. É interessa ter em mente, sobretudo após as maiores preocupações ambientais, que as fontes de energia devem, na medida do possível, estar associadas a uma matriz limpa, renovável e, em última instância, sustentável.

De modo geral, podemos sintetizar a capacidade instalada dos países do MERCOSUL por meio da Tabela 8 , que segue abaixo.

Tabela 8 - Capacidade instalada, energia elétrica gerada e consumo de eletricidade por habitante em 2009

\begin{tabular}{|l|l|l|l|l|l|l|}
\hline País & Argentina & Brasil & Paraguai & Uruguai & Venezuela & $\begin{array}{l}\text { América } \\
\text { do Sul }\end{array}$ \\
\hline $\mathrm{MW}$ & 32.144 & 106.573 & 8.814 & 2.503 & 23.708 & 217.436 \\
\hline $\mathrm{GWh}$ & 122.286 & 466.158 & 54.842 & 8.022 & 124.823 & 950.853 \\
\hline $\mathrm{kWh} / \mathrm{hab}$ & 3.175 & 2.600 & 1.501 & 2.625 & 4.366 & 2.453 \\
\hline
\end{tabular}

Fonte: Elaboração própria com base em CIER (2011)

\section{TELECOMUNICAÇÕES}

Ao longo dos anos o setor de telecomunicações vem assumindo um papel cada vez mais importante nas dinâmicas sociais e econômicas. Logo, a difusão de tais serviços se tornou um aspecto fundamental para 0 desenvolvimento dos territórios. 
No que se refere à densidade da provisão dos referidos serviços, os dados presentes na Tabela 9 revelam o nível de atraso dos países do MERCOSUL em relação aos Países Desenvolvidos (PDs). Caso consideremos a densidade de usuários de internet e linhas fixas, por exemplo, é possível verificar que a média do bloco corresponde a cerca de metade daquela apresentada pelos PDs. O desempenho referente à banda larga é ainda pior, representando apenas $27 \%$. Um aspecto acalentador em tal cenário é a densidade de linhas móveis que, na maioria dos países sul-americanos observados, é compatível com aquele presente nos PDs.

Tabela 9 - Densidade do Serviço de Telefonia e Internet em 2011 (por 100 pessoas)

\begin{tabular}{|l|l|l|l|l|}
\hline Região & Internet & Banda Larga & Linhas Fixas & Linhas Móveis \\
\hline Países Desenvolvidos & 70 & 25 & 44 & 122 \\
\hline Argentina & 36 & 10 & 25 & 135 \\
\hline Brasil & 41 & 7 & 22 & 123 \\
\hline Paraguai & 20 & 0,4 & 5,6 & 99 \\
\hline Uruguai & 48 & 11 & 29 & 141 \\
\hline Venezuela & 36 & 5 & 25 & 98 \\
\hline Média MERCOSUR & 36 & 7 & 21 & 119 \\
\hline Fon
\end{tabular}

Fonte: UIT

Em relação às assimetrias presentes entre as nações do MERCOSUL, pode-se constatar que, apesar de certa paridade entre os dois países maiores (Argentina e Brasil), a divergência entre os dois menores (Paraguai e Uruguai) é muito relevante. A Venezuela, encontra-se em um nível intermediário, apesar de apresentar o pior resultado de densidade de linhas móveis.

Ao considerarmos as regiões que compõem os países do MERCOSUL, os poucos dados disponíveis mostram a existência de profundas disparidades entre elas. Em relação à densidade de internet, por exemplo, no Brasil, era possível constatar a prevalência das áreas centrais, em termos econômicos (São Paulo) e políticos (Distrito Federal), e das localidades próximas a estas em 2012. O abismo existente entre as regiões do país neste quesito era verificável no fato de o Distrito Federal apresentar um resultado 20 vezes superior ao do Amapá (ANATEL).

No Uruguai, caso observemos os dados subnacionais sobre as inscrições ao serviço de TV em 2011, visto que as informações referentes à internet por departamento não estão disponíveis, também é possível constatar a presença de assimetrias entre suas regiões na prestação de serviços de telecomunicações (ver Gráfico 12). Os dados de Argentina, Paraguai e Venezuela servirão como fonte de análise para os nossos próximos trabalhos, dada a sua atual indisponibilidade.

Revista de Estudos Sociais | Ano 2014, N. 32, V. 16, Pag. 


\section{Gráfico 12 - Densidade do Serviço de TV por Departamento Uruguaio em 2011}

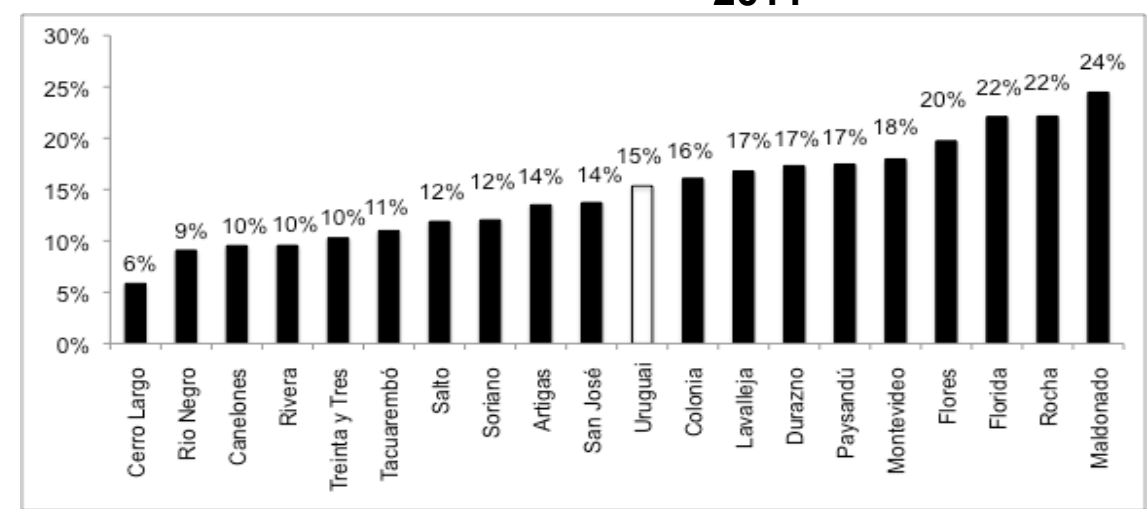

Fonte: URSEC

No caso dos países sul-americanos observados, é possível identificar alguns fatores que foram determinantes para o desempenho do setor de telecomunicações nas últimas décadas. A forte retração dos investimentos públicos a partir dos anos 80 , devido à crise econômica instaurada na região no referido período, certamente é um deles. Além disso, a partir daquele momento, a velocidade na qual o mencionado setor se dinamizava, aumentava de forma exponencial, provocando, portanto, a ampliação dos investimentos necessários a assegurar a competitividade dos territórios neste sentido. Seguindo a tendência presente no cenário internacional, a resposta encontrada por tais países foi a privatização macissa do setor de telecomunicações, sobretudo nos anos 1990's. O fato de a privatização ter propiciado uma difusão mais eficiente destes serviços é discutível, contudo os números mostram que a densidade do setor aumentou após tal processo.

Dada a ausência de informações sobre a difusão do setor de telecomunicações nas regiões que compõem os países do MERCOSUL, tornase difícil quantificar a dimensão das assimetrias existentes. Apesar dos poucos dados disponíveis, é possível perceber a existência de desequilíbrios na oferta destes serviços e, portanto, a necessidade de atuação dos governos na condução de um processo de convergência, visto que, em geral, as áreas que apresentam as menores densidades são aquelas que oferecem também os menores níveis de rentabilidade às empresas.

\section{FUNDO PARA A CONVERGÊNCIA ESTRUTURAL DO MERCOSUL (FOCEM)}

Criado em 2004, o Fundo para a Convergência Estrutural do MERCOSUL tem como objetivo principal financiar programas destinados à redução das assimetrias socioeconômicas, em benefício das economias menores e menos desenvolvidas do bloco (BID, 2012). O referido Fundo é alimentado por transferências provenientes das cinco nações participantes ${ }^{5}$, no

${ }^{5} \mathrm{~A}$ incorporação da Venezuela ao FOCEM ocorreu em 2013.

Ano 2014, N. 32 Vol 16, Pag. | Revista de Estudos Sociais 
entanto, tais contribuições são distribuídas de maneira substancialmente inversa em favor dos países menores (Paraguai e Uruguai).

\begin{abstract}
"Fosse o critério para concessão dos benefícios do FOCEM o mesmo adotado na maior parte das políticas de combate às assimetrias da UE, baseado objetivamente na desigualdade de renda entre países conforme medida pelo PIB per capita, o Uruguai não seria beneficiado. Ademais, os países relativamente grandes ou ricos no âmbito do MERCOSUL não são relativamente grandes ou ricos no âmbito global, ao contrário de Alemanha, França e Reino Unido." (SOUZA et al., 2010, p. 12).
\end{abstract}

Desde sua entrada em funcionamento até junho de 2013, o FOCEM recebeu contribuições dos Estados Partes por um total de US\$ 751 milhões (BID, 2014). Enquanto, no caso do MERCOSUL, a quantidade de recursos anuais destinada às iniciativas de redução de assimetrias regionais não ultrapassou $0,003 \%$ do PIB em 2010, na UE tal percentual foi de cerca 0,4\% (MORAES, 2014).

\begin{abstract}
"Com um orçamento inicial de cem milhões de dólares para investimentos nos quatro Estados-membros, o FOCEM não tem capacidade de financiar projetos de grande envergadura, mesmo que se concentre apenas na área de infraestrutura. (...) mantendose apenas com esse caráter compensatório, o Fundo cumpre sua função como um elemento de estabilização da integração - uma vez que beneficia os sócios que se viam como prejudicados no processo. Por outro lado, dotado de um baixo orçamento e com uma estrutura institucional limitada e centralizada nos Estados, o FOCEM não onera excessivamente os "sócios maiores" nem cria problemas para o controle que esses países exercem sobre o aparato institucional do Mercosul, o que poderia ocorrer caso fosse instituído um órgão de gestão com algumas características supranacionais" (TESSARI, 2012, p. 133-134).
\end{abstract}

As quatro linhas de financiamento do FOCEM são convergência estrutural, desenvolvimento da competitividade, coesão social e fortalecimento institucional. Em relação ao número total de projetos aprovados, tal número apresentou significativas variações ao longo do tempo. Em 2007, a quantidade de aprovações foi 18, enquanto nos seis anos sucessivos (2008-jun/2013), os valores correspondentes foram, respectivamente, 5, 2, 11, 3, 2 e 2 (BID, 2014) ${ }^{6}$

Alguns dos fatores que justificariam o reduzido número de projetos aprovados foram sinalizados pelo órgão que controla as contas do setor público na Argentina, segundo o qual a ineficiência concernente à divulgação das atividades do fundo e o baixo valor total atribuído ao país por exemplo, fazem com que o montante de financiamento solicitado pela Argentina ao FOCEM seja relevantemente inferior àquele disponível (AUDITORÍA GENERAL DE LA NACIÓN, 2010).

Em relação à forma de disposição dos referidos projetos entre os quatro programas (ver Tabela 10), a prioridade dada àquele relativo à convergência estrutural é notória e constatável através do fato que a maior parte dos recursos totais disponibilizados pelo fundo foi atribuída a tal campo de atuação.

\footnotetext{
${ }^{6}$ Sobre a execução dos projetos aprovados, até junho de 2013, somente 3 foram finalizados, enquanto 2 foram rescindidos (BID, 2013).
}

Revista de Estudos Sociais | Ano 2014, N. 32, V. 16, Pag. 
Tabela 10 - Projetos aprovados pelo FOCEM por país e por linha de financiamento, 2007-jun/2012 (em Milhões de US\$)

\begin{tabular}{|l|l|l|l|l|l|}
\hline Proponente & Total & $\begin{array}{l}\text { Convergência } \\
\text { Estrutural }\end{array}$ & Competitividade & $\begin{array}{l}\text { Coesão } \\
\text { Social }\end{array}$ & $\begin{array}{l}\text { Fortalecimento } \\
\text { Institucional }\end{array}$ \\
\hline Paraguai & 882,1 & 834,3 & 17,6 & 30,2 & 0 \\
\hline Uruguai & 195,1 & 184,9 & 5,3 & 4,9 & 0 \\
\hline Brasil & 45,7 & 16,1 & 7,6 & 22 & 0 \\
\hline Argentina & 42,9 & 34,3 & 0,7 & 7,9 & 0 \\
\hline Pluriestatal & 26,4 & 0 & 26,4 & 0 & 0 \\
\hline $\begin{array}{l}\text { Secretaria } \\
\text { MERCOSUL }\end{array}$ & 0,2 & 0 & 0 & 0 & 0,2 \\
\hline Total & 1192,4 & 1069,6 & 57,6 & 65 & 0,2 \\
\hline Em \% & $100 \%$ & $90 \%$ & $5 \%$ & $5 \%$ & $0 \%$ \\
\hline $\begin{array}{l}\text { Participação } \\
\text { FOCEM }\end{array}$ & & $73,9 \%$ & $83,3 \%$ & $72,6 \%$ & $100 \%$ \\
\hline
\end{tabular}

Fonte: BID (2014)

As atividades financiadas para a promoção do processo de convergência estrutural incluem: construção, adequação, modernização e recuperação de vias de transporte; exploração, transporte e distribuição de combustíveis fósseis e biocombustíveis; geração, transmissão e distribuição de energia elétrica; implantação de obras de infraestrutura hídrica para contenção e adução de água, de saneamento ambiental e de macrodrenagem.

Em relação ao total de projetos do programa de convergência estrutural aprovados até junho de 2011, 65\% contemplaram a área de transportes, enquanto os remanescentes 35\% foram distribuídos de maneira análoga entre os setores de energia elétrica e saneamento básico.

Entre aqueles referentes à construção, adequação, modernização e recuperação de vias de transporte, $91 \%$ foram destinados aos serviços rodoviários e $9 \%$ aos ferroviários. Confirmando que a predominância do transporte rodoviário no âmbito das políticas públicas da região ainda persiste.

A propósito da distribuição geográfica das atividades do programa de convergência estrutural, observa-se que o caráter distributivo do fundo foi respeitado, dado que $95 \%$ dos recursos foram disponibilizados para projetos paraguaios e uruguaios, com a predominância do primeiro em relação ao segundo. Sobre a distribuição a nível subnacional dos projetos do mencionado programa, no caso de Paraguai e Uruguai, a maioria deles se concentrava em localidades próximas às suas áreas mais relevantes em termos econômicos.

\section{CONSIDERAÇÕES FINAIS}

$\mathrm{Na}$ tentativa de delinear algumas das principais características concernentes às carências infraestruturais existentes no MERCOSUL, observou-se que, em relação a territórios mais desenvolvidos, como a União Europeia, por exemplo, a discrepância presente atualmente ainda é bastante elevada. 
Através dos dados nacionais referentes aos cinco países do bloco sulamericano, verificou-se que as provisões infraestruturais também são muito assimétricas entre eles. Apesar da pequena disponibilidade de dados a nível subnacional, foi possível confirmar o fato de que, em geral, as regiões mais desenvolvidas têm maior acesso à infraestrutura. Isso beneficia não apenas indicadores econômicos, como produção, mas, inclusive, sociais, como bemestar da população.

Diante deste cenário, no qual as profundas assimetrias existentes fazem com que o bloco necessite de políticas públicas que possibilitem a instauração de um processo de convergência, inclusive em termos de infraestrutura, foi criado o FOCEM. Todavia, tal fundo apresenta dois problemas cruciais, a saber, escassez de recursos e uma configuração que não privilegia de modo prevalente as áreas menos desenvolvidas do bloco.

Portanto, considera-se que alguns dos principais aspectos que impedem um mais efetivo processo de convergência infraestrutural no MERCOSUL estão relacionados com o aumento do volume de investimentos (públicos e privados) e com uma melhor planificação na utilização dos recursos disponíveis. Contudo, neste contexto, é necessário considerar que na base de tal processo se encontram os conflitos de interesse existentes entre os países e ao interno deles. Assim sendo, uma maior integração entre as nações que compõem o MERCOSUL é um dos principais desafios, mas não o único, impostos ao processo de convergência ao seu interno.

\section{BIBLIOGRAFIA}

$A C E B E B$, Para las provincias, la distribución de la riqueza no varía desde 2002, Buenos Aires: ACEBEB, 2008.

ALONSO L. G.; SÁNCHEZ R. J. El papel del transporte con relación a los Objetivos de Desarrollo del Milenio. Santiago do Chile: CEPAL, 2012.

ASOCIACIÓN DE LOGÍSTICA DE VENEZUELA - ALV. Estadísticas 20132014, Septiembre de 2014. Disponível em: <http://www.alvlogistica.org/docs/EstadisticasSept2014.pdf> acesso: 2014.

ADMINISTRACION NACIONAL DE ELECTRICIDAD - ANDE. Ver: <http://www.ande.gov.py/generacion.php> acesso: 2014.

ADMINISTRACIÓN NACIONAL DE NAVEGACIÓN Y PUERTOS - ANNP. Disponível

em:<http://www.annp.gov.py/index.php?option=com_content\&view=article\&id=1 2\&lang=es\&showall=1 > acesso: 2014.

Auditoría General de la Nación, Informe de Auditoria, Fundo de Convergência Estrutural do MERCOSUL. Buenos Aires, 2010.

BANCO INTERAMERICANO DE DESENVOLVIMENTO - BID, Informe MERCOSUL N 18. Buenos Aires, 2014.

Revista de Estudos Sociais | Ano 2014, N. 32, V. 16, Pag. 
BANCO INTERAMERICANO DE DESENVOLVIMENTO - BID, Informe MERCOSUL N 17. Buenos Aires, 2013.

BANCO INTERAMERICANO DE DESENVOLVIMENTO - BID, Informe MERCOSUL N 16. Buenos Aires, 2012.

BALANÇO ENERGÉTICO NACIONAL 2013 - BEN 2013. BEN 2013: Ano base 2012 / Empresa de Pesquisa Energética. - Rio de Janeiro: EPE, 2013. Disponível em:

https://ben.epe.gov.br/downloads/Relatorio_Final_BEN_2013.pdf> acesso: 2014.

CEPAL. Análisis de la Legislación Eléctrica en América Latina. Santiago, Chile: Cepal, 2009 (Documento LC/R 1.726).

COMISIÓN DE INTEGRACIÓN ENERGÉTICA REGIONAL - CIER. Información del sector energético en países deAmérica del Sur, América $C$ entral y El Caribe - Datos del año 2009, CIER, 2011.

DOER O. Políticas portuarias. CEPAL, Santiago do Chile, Série: recursos naturales e infraestructura, 2011.

EL PAIS. Anuário EI Pais 2005. Madrid, 2006. Disponível em: <http://www.elpais.com.uy /Anuarios/ 05/12/31/anua_naci_198464 .asp>, acesso: 2012.

EMPRESA DE PESQUISA ENERGÉTICA - EPE. Boletim de conjuntura energética $4^{\circ}$ trimestre 2011. Nota técnica DEA 07/12. Rio de Janeiro, julho de 2012.2 Disponível em: <http://www.epe.gov.br/mercado/Documents/S\%C3\%A9rie\%20Estudos \%20de\%20Energia/20120720_1.pdf> acesso: 2014.

LACERDA M. S. Ferrovias Sul-Americanas: A Integração Possível. Revista do BNDES, V. 16, N. 31, P. 185-214, 2009.

Latin America and Caribbean Air Transport Association - ALTA. ALTA Latin American \& Caribbean Capacity Analysis. Miami, 2011. Disponível em: <http://www.alta.aero/2010/sites/default/files/ALTA\%20Capacity\%20

Analysis\%202010_0.pdf>, acesso: 2014.

MALDONADO, P. Seguridad y calidad del abastecimiento eléctrico a más de 10 años de la reforma eléctrica en América del Sur. Santiago, Chile: Cepal, Serie Recursos Naturales e Infraestructura, 72, 2004.

MASI, F. Paraguay: cuando la energía no es igual al desarrollo. Observatório Económico de la Red Mercosur. Noviembre de 2011. Disponível em:

$<$ http://www.oered.org/index.php?option=com_content\&view=article\&id=170\&la $\mathrm{ng}=\mathrm{es}>$ acesso: 2014 .

MINISTÉRIO DE MINAS E ENERGIA - MME. Monitoramento do Sistema Elétrico Brasileiro. Boletim de Julho2012. Disponível em: $<$ http://www.mme.gov.br/see/galerias/arquivos/Publicacoes/Boletim_mensalDM SE/Boletim_de_Monitoramento_do_Sistema_Elxtrico_-_Julho-2012.pdf> acesso: 2014. 
MINISTERIO DEL PODER POPULAR PARA LA ENERGÍA ELÉCTRICA MPPEE. Anuario Estadístico 2013. Sector Eléctrico Venezolano - cifras correspondientes al año 2012. MPPEE, Oficina de Planificación, Presupuesto y Organización, Edición n. 3, 2013.

MORAES M. L. II processo di convergenza socio-economica nel MERCOSUR, a partire dalla sua istituzione: una verifica empirica a livello sub-nazionale. Roma: Aracne, 2014.

NATAL J. L. A. Transporte, ocupação do espaço e desenvolvimento capitalista no Brasil: história e perspectivas. Ensaios FEE, Vol. 12, No 2, 1991.

PERROTTI D. E.; SÁNCHEZ R. J. La brecha de infraestructura en América Latina y el Caribe. Santiago do Chile: CEPAL, 2011.

SANTIAGO P. B. Infraestrutura: Experiência na América Latina. Santiago do Chile: CEPAL, 2011.

SANTOS, T.; SANTOS, L.; MAHECHA, E. G. Integración Energética en Latinoamérica: breve historia y sus oportunidades en el siglo XXI. EM: 4th Latin-American Meeting of Energy Economics (ELAEE), 2013.

SANTIAGO, P. B., Infraestrutura: Experiência na América Latina. CEPAL, Santiago do Chile, 2011.2 Disponível em: <http://www.cepal.org/publicaciones/xml/9/43439/ CEPAL_35.pdf>, acesso: 2014.

SOUZA, A. M. et al. Integrando desiguais: assimetrias estruturais e políticas de integração no Mercosul. Rio de Janeiro: IPEA, 2010.

TESSARI G. R. Integração regional, fundos estruturais e estabilidade institucional no Mercosul: a criação do FOCEM. São Paulo: Perspectivas, v. 42, p. 115-137, 2012.

WORLD ECONOMIC FÓRUM - WEF, The Global Competitiveness Report 2013-2014. Genebra, 2014.

Revista de Estudos Sociais | Ano 2014, N. 32, V. 16, Pag. 